Provided for non-commercial research and education use. Not for reproduction, distribution or commercial use.

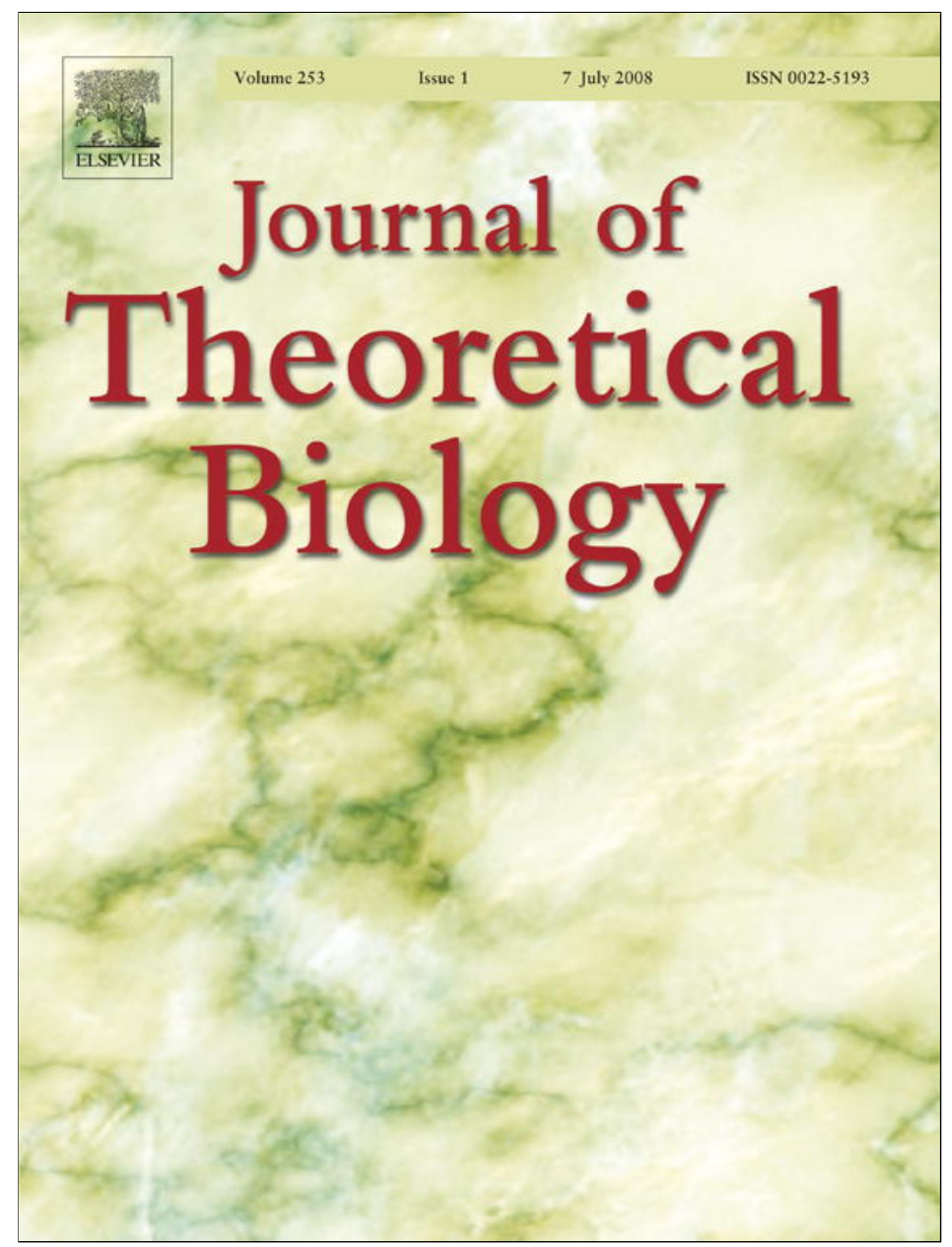

This article appeared in a journal published by Elsevier. The attached copy is furnished to the author for internal non-commercial research and education use, including for instruction at the authors institution and sharing with colleagues.

Other uses, including reproduction and distribution, or selling or licensing copies, or posting to personal, institutional or third party websites are prohibited.

In most cases authors are permitted to post their version of the article (e.g. in Word or Tex form) to their personal website or institutional repository. Authors requiring further information regarding Elsevier's archiving and manuscript policies are encouraged to visit:

http://www.elsevier.com/copyright 


\title{
Integrating cell-cycle progression, drug penetration and energy metabolism to identify improved cancer therapeutic strategies
}

\author{
Raja Venkatasubramanian, Michael A. Henson, Neil S. Forbes* \\ Department of Chemical Engineering, University of Massachusetts, 159 Goessmann Hall, Amherst, 686 North Pleasant Street, \\ Amherst, MA 01003-9303, USA
}

Received 8 June 2007; received in revised form 12 February 2008; accepted 12 February 2008

Available online 21 February 2008

\begin{abstract}
The effectiveness of chemotherapeutic drugs in tumors is reduced by multiple effects including drug diffusion and variable susceptibility of local cell populations. We hypothesized that quantifying the interactions between drugs and tumor microenvironments could be used to identify more effective anti-cancer strategies. To test this hypothesis we created a mathematical model that integrated intracellular metabolism, nutrient and drug diffusion, cell-cycle progression, cellular drug effects, and drug pharmacokinetics. To our knowledge, this is the first model that combines these elements and has coupled them to experimentally derived parameters. Drug cytotoxicity was assumed to be cell-cycle phase specific, and progression through the cell cycle was assumed to be dependent on ATP generation. The model consisted of a coupled set of nonlinear partial differential, ordinary differential and algebraic equations with an outer free boundary, which was solved using orthogonal collocation on a moving grid of finite elements. Model simulations showed the existence of an optimum drug diffusion coefficient: a low diffusivity prevents effective penetration before the drug is cleared from the blood and a high diffusivity limits drug retention. This result suggests that increasing the molecular weight of the anti-cancer drug paclitaxel from 854 to approximately 20,000 by nano-particle conjugation would improve its efficacy. The simulations also showed that fast growing tumors are less responsive to therapy than are slower tumors with more quiescent cells, demonstrating the competing effects of regrowth and cytotoxicity. The therapeutic implications of the simulation results are that (1) monolayer cultures are inadequate for accurately determining therapeutic effects in vitro, (2) decreasing the diffusivity of paclitaxel could increase its efficacy, and (3) measuring the proliferation fraction in tumors could enhance the prediction of therapeutic efficacy.
\end{abstract}

(C) 2008 Elsevier Ltd. All rights reserved.

Keywords: Cell cycle; Drug penetration; Chemotherapy; Pharmacokinetics; Tumor growth model

\section{Introduction}

The effectiveness of most chemotherapeutic drugs is dependent on the distribution of local microenvironments in tumors (Brown, 2002; Sutherland, 1988; Tannock, 1986). There are two major properties of these microenvironments that reduce therapeutic efficacy: low drug concentrations due to diffusion resistance and reduced responsiveness of cancer cells to the administered drug (Grantab et al., 2006; Jain, 1999; Lankelma, 2002; Minchinton and Tannock, 2006; Tannock, 1986, 2001; Tannock et al., 2002). A model containing both of these phenomena could address whether

\footnotetext{
*Corresponding author. Tel.: + 14135770132 ; fax: + 14135451647.

E-mail address: forbes@ecs.umass.edu (N.S. Forbes).
}

drug concentration gradients affect cell susceptibility. Additionally, understanding the interaction of these barriers to therapy will enable development of novel strategies to overcome them (Jain, 1996).

Resistance to interstitial diffusion is known to significantly reduce drug efficacy in tumors (Au et al., 2002; Grantab et al., 2006; Lankelma, 2002; Nederman and Carlsson, 1984; Nicholson et al., 1997; Tannock et al., 2002). Many potential therapeutic agents that kill cancer cells in monolayer culture flasks do not effectively reduce tumor growth when tested in mice (Olive and Tuveson, 2006; Suggitt and Bibby, 2005). This reduced efficacy can be attributed in part to drug transport limitations. The anti-cancer drug paclitaxel (Pac) is known to have gradients in tissues that affect its efficacy (Au et al., 2002; 
Grantab et al., 2006; Nicholson et al., 1997). Experiments with multi-cellular layer cultures have shown that drug transport through tumor tissue poses a substantial barrier to chemotherapeutic effectiveness for even fast penetrating drugs like 5-fluorouracil (5FU) (Nederman and Carlsson, 1984; Tunggal et al., 1999). Diffusion resistance in tumors is compounded by the chaotic vascular network which has large intercapillary distances compared to normal tissue and therefore more cellular regions distant from the blood supply (Jain, 1999; Konerding et al., 1999).

The responsiveness of cancer cells to chemotherapeutics strongly depends on the cell's position in the cell cycle (Shah and Schwartz, 2001). Most anticancer agents only target proliferating tumor cells and do not affect poorly nourished quiescent cells that are distant from vasculature (Jackson, 1989; Tannock, 1986). More specifically, many therapeutics affect cells in specific cell-cycle phases. For example, 5FU targets cells in S phase (Daniel et al., 2003; Tanaka et al., 2000) and paclitaxel inhibits microtubule formation, which is toxic to cells in the G2 and M phases (Nogales, 2000; Zhao et al., 2005).

Cell-cycle progression is divided into different phases (Fig. 1) namely, G0, G1, S, G2, and M, each characterized by the different functions necessary for progression through cell division under different environmental conditions. In three-dimensional tissue the growth rate and the transition rates through the cell-cycle phases depend on local nutrient availability and the amount of cellular energy (ATP) provided by intracellular metabolism (Costello and Franklin, 1994; Venkatasubramanian et al., 2006). Nutrient availability is controlled by diffusion of nutrients through successive layers of cells in the tissue. When supplied with sufficient nutrients, cells will replicate rapidly and more cells will be in the $\mathrm{S}, \mathrm{G} 2$, and $\mathrm{M}$ phases. In environments with less nutrients, cells will spend more time

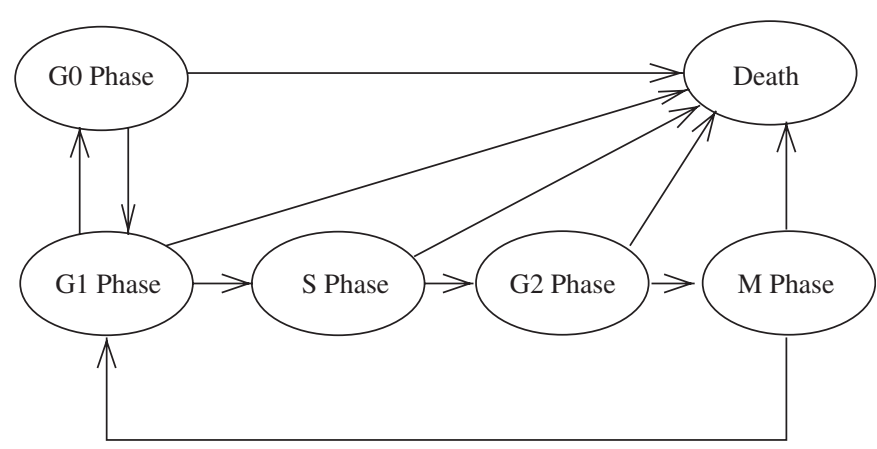

Fig. 1. Cell-cycle model incorporated in the spheroid growth model. The entire spheroid volume was assumed to be comprised of either dead cells or cells in the different phases of the cell cycle: G0, G1, S, G2, and M. Each line signifies a transition from of one cell-cycle phase to another. In good nutrient conditions cells will proliferate by traversing from G1 to S to $\mathrm{G} 2$ to $\mathrm{M}$ to $\mathrm{G} 1$. In the final transition from $\mathrm{M}$ to $\mathrm{G} 1$ phase cells replicate. In good nutrient conditions quiescent G0 cells can become proliferating by entering the G1 phase. In moderately poor nutrient conditions G1 cells will traverse to the quiescent, G0 phase. In acutely poor nutrient conditions (or in the presence of a cytotoxic drug) cells from all cell-cycle phases will die. in G1 and may enter G0 (Carlsson, 1977; Darzynkiewicz et al., 1980; Dethlefsen et al., 1980). This effect has been demonstrated experimentally: at the outer, well-nourished edge of spheroids, the population of cells in the S, G2, and $M$ phases has been shown to be higher than in the interior of spheroids, where the relative population of G1 cells is higher (Carlsson, 1977; Freyer, 1998; LaRue et al., 2004; Wibe et al., 1981). This organization is also seen in tumors grown in mice. The relative population of rapidly growing cells has been shown to be greater near blood vessels than deep within tumor tissue (Sutherland, 1988).

When investigating drug efficacy, the effects of drugs on normal cells in the body cannot be ignored. If only the local tumor environment is considered, the obvious treatment solution would be continuous administration of cytotoxic drugs at very high concentrations. This problem is encountered when interpreting drug studies in monolayer cultures: most compounds show efficacy against cancer cells but are systemically too toxic for clinical use (El-Khoueiry and Lenz, 2006; Kearns et al., 1995; Kim and Tannock, 2005). In practice all cancer therapies are toxic to normal cells at some concentration and must be administered in periodic cycles (Kim and Tannock, 2005). For example, paclitaxel is typically administered for $24 \mathrm{~h}$ every 3 weeks (Perez, 1998) and 5FU is administered for $24 \mathrm{~h}$ every week (Leichman, 1999; Thomas and Zalcberg, 1998). These intervals allow for normal cells in the body and the immune system to recover between treatments (Kim and Tannock, 2005).

To adequately account for the effects of the body and the cardiovascular system, pharmacokinetics must also be included. The concentration of a drug in the blood cannot be directly controlled. Once an intravenous (IV) injection has been started a lag exists until the concentration in the blood reaches a maximum. Throughout the infusion, drug is constantly being cleared from the blood via the action of the liver and the kidneys which metabolize and excrete it (Gianni et al., 1995; Lau et al., 2001). Pharmacokinetics can be accurately described mathematically using two- and three-compartment models (Kearns et al., 1995; Terret et al., 2000).

We have developed a tumor model that incorporates spatial heterogeneity, drug diffusion, drug pharmacokinetics, cell-cycle-phase transitions and the diffusion of multiple nutrients to address the hypothesis that understanding the interactions between drugs and the heterogeneous microenvironments in tumors can be used to formulate effective therapeutic strategies. The current model describes the growth of in vitro multi-cellular tumor spheroids and in vivo avascular tumor nodules. Energy metabolism is described using our previously developed spheroid model for the diffusion of glucose, oxygen, and lactate and the associated generation of ATP (Venkatasubramanian et al., 2006). The tumor model consists of a coupled set of nonlinear partial differential, ordinary differential, and algebraic equations with a free outer boundary. An iterative calculation procedure with spatial discretization 
and a moving grid was used to numerically solve the model equations. Model parameters were estimated from experimental data available in the literature. The components of the model were validated with a range of simulations that were compared to experimental observations.

\section{Previous tumor models}

Previous mathematical studies designed to understand the effect of cell-cycle-specific or non-specific drugs on tumor growth (Table 1) can be broadly divided into two categories: (1) models that considered the tumor as a homogeneous population of cells without spatial heterogeneity, and (2) models that incorporated spatial heterogeneity, drug diffusion, and other transport effects.

The homogenous models included more sophisticated mechanisms describing the cell cycle and drug effects than the spatially distributed models (Table 1). Most of these models were based on experiments with cells grown in monolayer cultures and did not include nutrient or drug

Table 1

Summary of tumor growth and drug cytotoxicity models

\begin{tabular}{|c|c|c|}
\hline Author(s) & Elements included & Result/discovery \\
\hline \multicolumn{3}{|c|}{ Homogeneous models } \\
\hline $\begin{array}{l}\text { Levasseur et al. } \\
\text { (1998) }\end{array}$ & $\begin{array}{l}\text { Integrated } \\
\text { experiments and } \\
\text { modeling } \\
\text { Monolayer simulation }\end{array}$ & $\begin{array}{l}\text { Altering the time of } \\
\text { exposure to the agents can } \\
\text { be used to modulate drug } \\
\text { effect, response } \\
\text { heterogeneity, and drug } \\
\text { resistance }\end{array}$ \\
\hline Gardner (2000) & $\begin{array}{l}\text { Cell death } \\
\text { Cell-cycle phases }\end{array}$ & $\begin{array}{l}\text { An optimal, finite duration } \\
\text { of drug exposure maximizes } \\
\text { cell kill }\end{array}$ \\
\hline $\begin{array}{l}\text { Basse } \\
\text { et al. (2003), } \\
\text { Basse et al. } \\
(2004)\end{array}$ & $\begin{array}{l}\text { Cell death } \\
\text { Cell-cycle progression } \\
\text { Population balance } \\
\text { Parameter estimation }\end{array}$ & $\begin{array}{l}\text { Flow-cytometric data were } \\
\text { analyzed to obtain } \\
\text { transition rate parameters } \\
\text { between different cell-cycle } \\
\text { phases and apoptosis }\end{array}$ \\
\hline Panetta (1997) & $\begin{array}{l}\text { Proliferating and } \\
\text { quiescent cell } \\
\text { populations } \\
\text { Paclitaxel cytotoxicity }\end{array}$ & $\begin{array}{l}\text { Frequent drug infusion } \\
\text { (once every } 1 \text { or } 2 \text { weeks) is } \\
\text { more effective for paclitaxel } \\
\text { than the conventional } \\
\text { infusion (once in } 3 \text { weeks) }\end{array}$ \\
\hline
\end{tabular}

Transport-based models

Jackson and Tumor growth

Byrne (2000) Pharmacokinetics

Drug cytotoxicity

Tumor regression

Jackson (2003) Tumor growth

Pharmacokinetics
Table 1 (continued)

\begin{tabular}{lll}
\hline Author(s) & Elements included & Result/discovery \\
\hline Tzafriri et al. & Interstitial drug & An optimized intratumoral \\
(2005) & transport & drug release rate from \\
& & paclitaxel-loaded \\
& microspheres was \\
& & determined that maximizes \\
& killing of tumor cells
\end{tabular}

Lankelma et al. Interstitial drug (2000) transport

Kuh et al. (1999) Interstitial drug transport

Bertuzzi et al. (2003)

Ward and King
(2003)

Effects of oxygen on proliferation and death

Volume reduction due to dead cells disintegration Cytotoxicity of radiation and drugs Proliferating and quiescent cell populations

Tumor growth
Drug cytotoxicity

Doxurubicin takes as long as $200 \mathrm{~h}$ to penetrate to the center of tumors

As great as a 15 -fold difference in drug concentration exists at the periphery and center of tumor islets

High tumor cell density is a barrier to paclitaxel penetration Apoptosis induced by paclitaxel enhances drug penetration

Drug accumulation is saturable

New insight was found regarding complex treatment-related events, including cell reoxygenation and repopulation

\author{
Multicellular spheroids have \\ an enhanced survival rate \\ compared to monolayer \\ cultures
}

Models are classified into two categories (1) homogeneous models (no spatial heterogeneity) and (2) transport based models (explicitly incorporation of spatial heterogeneity).

transport. The effects of drug concentration and exposure time on monolayer cultures have been described by both phenomenological Hill coefficient models (Levasseur et al., 1998) and mechanistic models that incorporate cell-cycle phases (Gardner, 2000). These drug-effect models predicted that chemotherapeutic strategies could be tailored to individuals and suggested that altering drug scheduling may be more effective than dose escalation (Gardner, 2002b). Multiple compartment, cell-cycle-phase models have been developed that were based on cellular DNA content in order to couple with flow-cytometry data (Basse et al., 2003) and predict the effect of paclitaxel on monolayer cultures (Basse et al., 2004). A mathematical model that divided tumor mass into resistive and sensitive cell populations suggested that frequent drug infusion would be more effective in the treatment of breast and ovarian cancer with paclitaxel (Panetta, 1997). 
Models incorporating spatial heterogeneity have also been developed to study the effects of drug diffusion and drug-induced cell death in tumors (Table 1). Jackson and Byrne (2000) developed a tumor model incorporating vasculature with drug-resistant and drug-sensitive cell types to study the effect of emergent resistance on chemotherapeutic response. A spatio-temporal model of tumor response to sequestered, intracellular doxorubicin predicted that the response to chemotherapy is sensitive to the threshold level of doxorubicin required to initiate apoptosis at the maximum rate (Jackson, 2003). A reaction-diffusion-based model that incorporated drug diffusion through tumor interstitium, intracellular uptake, and drug clearance through the microvasculature was used to determine the optimum drug release rate from intratumorally injected microspheres (Tzafriri et al., 2005). Models of doxorubicin (Lankelma et al., 2000) and paclitaxel (Au et al., 2001) transport through tumor tissue, which incorporate intracellular drug binding, predicted that these drugs penetrate slowly and have long retention times in tissue. These previous models individually accounted for spatial heterogeneity, drug transport limitations, cell-cycle progression, and pharmacokinetics. However, to our knowledge no existing tumor models capture all of these effects. Understanding the interaction of these elements is critical to for the design of effective therapeutic strategies.

\section{Model structure}

The present model is an extension of our previous model that predicted the extent and location of quiescence assuming that cell growth and death are dependant on intracellular energy metabolism (Venkatasubramanian et al., 2006). In this study we have incorporated cell-cycle progression, drug transport, pharmacodynamics, and pharmacokinetics to develop a model capable of predicting the effect of heterogeneous microenvironments on drug efficacy. The model consists of cell and mass balance equations formulated in spherical coordinates under the assumption of radial symmetry.

$\frac{\partial n_{i}}{\partial t}+\nabla \cdot\left(v n_{i}\right)=g_{i}$

$\nabla \cdot(v)=\phi_{\text {generation }}^{\text {volume }}-\left.\phi_{\text {loss }}^{\text {volume }} \quad v\right|_{r=0}=0$

$\frac{\partial R}{\partial t}=\left.v\right|_{r=R}$

$\sum V_{i} n_{i}=1$

$\frac{\partial C_{j}}{\partial t}+D_{j} \Delta^{2} C_{j}+\nabla \cdot\left(v C_{j}\right)=\left.0 \quad \frac{\partial C_{j}}{\partial r}\right|_{r=0}=0$

$\left.C_{j}\right|_{r=R}=f(t)$
$D_{k} \Delta^{2} C_{k}=\left.Q_{k} \quad \frac{\partial C_{k}}{\partial r}\right|_{r=0}=\left.0 \quad C_{k}\right|_{r=R}=C_{k, B u l k}$

Eq. (1) represents the conservation of cell number within each cell-cycle phase, where $n_{i}$ is the number of cells in the $i$ th cell-cycle phase per unit volume. The six cell phases included G0, G1, S, G2, M, and dead cells. The terms on the left-hand side of Eq. (1) are the accumulation of cells in each cell-cycle phase and the convective transport of cells due to expansion of tumor tissue, where $v$ represents the bulk convective velocity of the cell population. The righthand side represents the net change in the number of cells in each phase due to transitions between the phases as well as cell death.

Eq. (2) represents a convective flux that is created by volume changes during cell growth $\left(\phi_{\text {generation }}^{\text {volume }}\right)$ and death $\left(\phi_{\text {loss }}^{\text {volume }}\right)$ and which results in a gradient in the cell mass velocity $(v)$. The rate of tumor growth is determined by evaluating the cell mass velocity at the periphery (Eq. (3)). Cells were assumed to be tightly packed such that void space could be neglected (Eq. (4)). Here $V_{i}$ is the volume of an individual cell in the $i$ th phase. Tissue volume was assumed to be entirely occupied by cells, and drug was assumed to be associated with the cells. The drug transport equation (Eq. (5)) accounts for diffusive transport driven by the gradient in drug concentration and convective transport due to cell motion. The apparent drug diffusion coefficient, $D_{j}$, represents the combined effect of drug binding, drug uptake, and drug diffusion in the tissue.

Nutrient diffusion was assumed to be balanced by cellular uptake (Eq. (6)), where $\mathrm{C}_{k}, D_{k}$, and $Q_{k}$ are the local concentration, the diffusion coefficient, and the uptake rate of nutrient $k$, respectively. The model assumes that tumor cells can consume three nutrients: glucose, oxygen, and lactate (Venkatasubramanian et al., 2006). Because the molecular weights of the nutrients are small, their transport is assumed to be fast compared to tumor growth. This pseudo-steady state assumption implies that nutrients do not accumulate in the tissue (Venkatasubramanian et al., 2006). The pseudo-steady state assumption was not applied to the drug mass balance (Eq. (4)) to account for the possibility that the time scale for drug diffusion is comparable to that for tumor growth.

For all balances, a Neumann-type symmetry condition was imposed at the tumor center. This constraint was implemented as a zero-gradient boundary condition for the cell, nutrient and drug balances, and a zero-velocity boundary condition for the volume balance. The second boundary condition for the drug balance (Eq. (5)), is a time-dependent pharmacokinetic function, $f(t)$, that accounts for drug infusion and washout. Nutrient concentrations were assumed to be constant at the tumor periphery and equal to the bulk concentration $\left(C_{j, B u l k}\right.$, Eq. (6)). In the following sections the individual components of this model are described in detail. 


\subsection{Cell metabolism}

A description of primary energy metabolism that encompassed glycolysis and the tricarboxylic acid (TCA) cycle was used to calculate local nutrient uptake rates, $Q_{k}$. Each uptake rate was determined from (1) the availability of the nutrient in the extra-cellular environment and (2) stoichiometric limitations of intracellular metabolism. The metabolic model was based on the assumption that glucose and oxygen can be consumed and that lactate can be either produced or consumed. The following three lumped reactions describe the metabolic pathways included in the model:

Glycolysis : Glucose $\rightarrow 2$ Lactate +2 ATP

Glucose oxidation : Glucose $+6 \mathrm{O}_{2} \rightarrow 6 \mathrm{CO}_{2}$

$$
+6 \mathrm{H}_{2} \mathrm{O}+38 \mathrm{ATP}
$$

Lactate oxidation : $\quad$ Lactate $+3 \mathrm{O}_{2} \rightarrow 3 \mathrm{CO}_{2}$

$$
+3 \mathrm{H}_{2} \mathrm{O}+18 \mathrm{ATP}
$$

The maximal uptake rates of each nutrient were assumed to follow Michaelis-Menten-like functions, which describe the enzymatic control of glucose uptake and the saturation of oxygen and lactate uptake at high concentrations (Helmlinger et al., 2002).

$$
\begin{aligned}
Q_{\text {Gluc }}^{\text {max }} & =\frac{Q_{G l u c}^{\text {max }} C_{G l u c}}{K_{G l u c}+C_{G l u c}} \quad Q_{O x}^{\text {max-uptake }}=\frac{Q_{O x}^{\text {max }} C_{O x}}{K_{O x}+C_{O x}} \\
Q_{\text {Lac }}^{\text {max-uptake }} & =\frac{Q_{\text {Lac }}^{\text {max }} C_{L a c}}{K_{\text {Lac }}+C_{L a c}}
\end{aligned}
$$

Actual uptake rates $\left(Q_{G l u c}, Q_{O x}\right.$, and $\left.Q_{\text {Lac }}\right)$ were limited by the stoichiometry of intracellular metabolism (Eq. (8)), which was based on three simple assumptions: (1) cells consume glucose when it is available, (2) the oxygen uptake rate is limited by the maximal oxygen uptake rate or by the combined maximal uptake rates of the two carbon sources, and (3) lactate can be consumed as a carbon source when the concentration of glucose is low and the concentration of oxygen is high. These assumptions produced the following rules for the actual uptake rates:

$$
\begin{aligned}
Q_{G l u c} & =Q_{G l u c}^{\text {max-uptake }} \\
Q_{O x} & =\min \left(Q_{O x}^{\text {max-uptake }}, 6 Q_{G l u c}+3 Q_{\text {Lac }}^{\text {max-uptake }}\right) \\
Q_{\text {Lac }} & =-2 Q_{\text {Gluc }}+Q_{O x} / 3
\end{aligned}
$$

ATP production was determined by considering the formation and oxidation of pyruvate and assuming that the rate of the TCA cycle was equivalent to the oxygen uptake rate. The conversion of glucose to pyruvate, the conversion of lactate to pyruvate, and the oxidation of pyruvate were assumed to produce 8, 3, and 15 ATP molecules, respectively. The ATP generation rate was approximated from the three uptake rates and simplified using the third expression of Eq. (8) as follows:

$Q_{A T P}=8 Q_{G l u c}+5 Q_{O x}+3 Q_{\text {Lac }}=2 Q_{G l u c}+6 Q_{O x}$
These relationships and assumptions are described in more detail in our previous publication (Venkatasubramanian et al., 2006). The amount of available energy (ATP) is subsequently used to determine the rates of cell-cycle transitions, cell growth and cell death.

\subsection{Cell-cycle transitions}

The population of live cells in the tumor was divided into fractions corresponding to the different cell-cycle phases: G0, G1, S, G2, and $\mathrm{M}$ (Fig. 1). Cell balances (Eq. (1)) describe the number density of cells in each phase as a function of radial position and time. The transition rates between the phases are described by kinetic expressions dependent on the local ATP generation rate (Eq. (10)):

$$
\begin{aligned}
g_{G 1} & =\left(2 \mu_{G 1}^{M} n_{M}+\mu_{G 1}^{G 0} n_{G 0}\right)-\left(\mu_{S}^{G 1} n_{G 1}+\hat{\mu}_{D}^{G 1} n_{G 1}+\hat{\mu}_{G 0}^{G 1} n_{G 1}\right) \\
g_{S} & =\mu_{S}^{G 1} n_{G 1}-\left(\mu_{G 2}^{S} n_{S}+\hat{\mu}_{D}^{S} n_{S}\right) \\
g_{G 2} & =\mu_{G 2}^{S} n_{S}-\left(\mu_{M}^{G 2} n_{G 2}+\hat{\mu}_{D}^{G 2} n_{G 2}\right) \\
g_{M} & =\mu_{M}^{G 2} n_{G 2}-\left(\mu_{G 1}^{M} n_{M}+\hat{\mu}_{D}^{M} n_{M}\right) \\
g_{G 0} & =\hat{\mu}_{G 0}^{G 1} n_{G 1}-\left(\mu_{G 1}^{G 0} n_{G 0}+\hat{\mu}_{D}^{G 0} n_{G 0}\right)
\end{aligned}
$$

The transition rates between the phases are given by the following terms:

$\begin{aligned} \mu_{t o}^{\text {from }} & =\frac{\mu_{t o, \text { max }}^{\text {from }} Q_{A T P}}{K_{\text {from }, t o}+Q_{A T P}} \\ \hat{\mu}_{t o}^{\text {from }} & =\mu_{t o, \text { max }}^{\text {from }}\left(1-\frac{\sigma Q_{A T P}}{K_{\text {from }, t o}+Q_{A T P}}\right)\end{aligned}$

Here $\sigma$ is the basal survival rate (Venkatasubramanian et al., 2006). All transitions through the cell-cycle increase with increasing ATP production $(\mu)$, whereas the transitions to G0 and death increase with decreasing ATP production $(\hat{\mu})$.

There are two possible fates for G1 cells depending on energy availability. Under favorable environmental conditions (high ATP generation rates), G1-phase cells will enter $\mathrm{S}$ phase and commence cell division. Under unfavorable conditions (low ATP generation rates), G1-phase cells will enter the quiescent G0 phase. If a G0 cell returns to favorable conditions, it will reenter G1 and continue to replicate through the cell cycle. Actively proliferating cells will progress sequentially through the G1, S, G2, and M phases (Eq. (10)). With available energy, M-phase cells divide and produce two G1 cells. Under unfavorable conditions or when exposed to therapeutics, cells in all phases will die (Eq. (10)).

Simulations were started with a spherical tissue mass the size of a single cell in G1 phase, which produced the following initial condition:

$$
\begin{aligned}
& \left.n_{G 1}\right|_{t=0}=1 / V_{G 1} \\
& \left.n_{G 0}\right|_{t=0}=\left.n_{S}\right|_{t=0}=\left.n_{G 2}\right|_{t=0}=\left.n_{M}\right|_{t=0}=0
\end{aligned}
$$


The units of $n_{i}$ are cells per unit volume. It was assumed that cells in different phases had different volumes:

$V_{D}<V_{G 0}<V_{G 1}<V_{S}<V_{G 2}<V_{M}$

Because the model describes the evolution of cell populations rather than individual cells, the volumes in Eq. (13) represent the average volumes of cells in each cellcycle phase. Progression through the cell cycle was assumed to produce a linear increase in the average cell volume, with typical lengths of the different cell-cycle phases used to estimate the cell volumes. Accordingly, the values listed in Table 2 satisfy the following constraints: (1) the average volume of G1 phase cells is greater than one-half the volume of M-phase cells; and (2) the average volume of G2 phase cells is greater than average volume of $\mathrm{S}$ phase cells. Furthermore, quiescent cells have been reported to have one-half the volume of proliferating cells (Bauer et al., 1982).

Tumor expansion was assumed to be driven by the relative rates of growth and death, which results in generation and destruction of volume, respectively:

$$
\begin{aligned}
\phi_{\text {generation }}^{\text {volume }}= & \mu_{G 1}^{M} n_{M}\left(2 V_{G 1}-V_{M}\right)+\mu_{G 1}^{G 0} n_{G 0}\left(V_{G 1}-V_{G 0}\right) \\
& +\mu_{S}^{G 1} n_{G 1}\left(V_{S}-V_{G 1}\right)+\mu_{G 2}^{S} n_{S}\left(V_{G 2}-V_{S}\right) \\
& +\mu_{M}^{G 2} n_{G 2}\left(V_{M}-V_{G 2}\right) \\
\phi_{\text {loss }}^{\text {volume }}= & \hat{\mu}_{D}^{G 0} n_{G 0}\left(V_{G 0}-V_{D}\right)+\hat{\mu}_{S}^{G 1} n_{G 1}\left(V_{G 1}-V_{D}\right) \\
& +\hat{\mu}_{D}^{S} n_{S}\left(V_{S}-V_{D}\right)+\hat{\mu}_{D}^{G 2} n_{G 2}\left(V_{G 2}-V_{D}\right) \\
& +\hat{\mu}_{D}^{M} n_{M}\left(V_{M}-V_{D}\right)+\hat{\mu}_{G 0}^{G 1} n_{G 1}\left(V_{G 1}-V_{G 0}\right) \\
& +\mu_{D, \text { loss }} n_{D} V_{D}
\end{aligned}
$$

All tumor volume changes, $\phi$, are continuous, because each discrete volume difference between two phases $\left(V_{i}-V_{j}\right)$ is multiplied by a continuous phase transition rate, $\mu$. The final term in the volume loss expression represents degradation of necrotic material as described below.

\subsection{Tumor growth saturation}

Long-term growth of tumors is primarily attributed to angiogenesis which creates nutrient rich microenvironments (Durand, 1990; Folkman, 1971). The present model and most other tumor models do not consider angiogenesis. Such models without explicit expressions for volume loss result in tumors with perpetually increasing volume (Venkatasubramanian et al., 2006; Ward and King, 1997). A mechanism for the degradation of necrotic debris was included in the present model to account for growth saturation observed in spheroids (Durand, 1990).

The cell population was assumed to be comprised of both live and dead cells. Dead cells are created instantaneously following cell death and have a fixed volume $V_{D}$. Necrotic material is assumed to degrade linearly with a constant rate of $\mu_{D \text {,loss }}$, which resulted in the following expression for dead cell formation (Eq. (1)):

$$
\begin{aligned}
g_{D}= & \left(\hat{\mu}_{D}^{G 0} n_{G 0}+\hat{\mu}_{D}^{G 1} n_{G 1}+\hat{\mu}_{D}^{S} n_{S}+\hat{\mu}_{D}^{G 2} n_{G 2}+\hat{\mu}_{D}^{M} n_{M}\right) \\
& -\mu_{D, \text { loss }} n_{D}
\end{aligned}
$$

Here, $n_{D}$ is the number density of dead cells. No dead cells were present in the tumor initially:

$\left.n_{D}\right|_{t=0}=0$

\subsection{Saturated tumor initial condition}

The initial condition for the drug concentration depended on the goal of the simulation. Three different types of simulations were run to determine the effects of chemotherapeutics on (1) cancer cells grown as a monolayer, (2) cancer cells grown as multi-cellular spheroids, and (3) cancer cells in human tumors. The monolayer and spheroid simulations were run to compare to previous experimental observations. The simulations with human tumors were run to predict therapeutic efficacy of different treatment strategies. For the simulation of monolayer cultures, cells were assumed to grow at their maximal rate under the assumption of negligible nutrient depletion in the external media. All transport terms in the model were eliminated and the cells were assumed to be exposed to a uniform drug concentration:

$\frac{\partial n_{i}}{\partial t}=g_{i} \quad \mu_{\text {from }}^{t o}=\mu_{\text {from, } \max }^{t o} \quad \hat{\mu}_{\text {from }}^{t o}=0$

All simulations with spheroids and tumors started with a saturated spherical tumor mass at steady state. The initial condition was changed to be a saturated spheroid to expedite simulations:

$$
\begin{aligned}
\left.n_{i}(r)\right|_{t=0} & =n_{i}^{\text {Sat }}(r) \\
\left.v(r)\right|_{t=0} & =v^{\text {Sat }}(r) \\
\left.C_{j}(r)\right|_{t=0} & =C_{j}^{S a t}(r) \\
\left.C_{k}(r)\right|_{t=0} & =C_{k}^{S a t}(r)(18)
\end{aligned}
$$

The difference between the spheroid and tumor simulations was the peripheral drug boundary conditions. For spheroids, drug was added to and removed from the system as a pulse function with duration $t_{\text {pulse }}$ to mimic the addition and removal of drug containing medium from the culture:

$$
\begin{aligned}
& \left.C_{j}\right|_{r=R, 0<t<t_{\text {pulse }}}=C_{j, \text { Bulk }} \\
& \left.C_{j}\right|_{r=R, t>t_{\text {pulse }}}=0
\end{aligned}
$$

\subsection{Pharmacokinetics}

For simulations of drug effects on human tumors the drug concentration at the periphery was given by a pharmacokinetic model. Multi-compartment models are 
Table 2

Model parameters and their literature sources

\begin{tabular}{|c|c|c|c|}
\hline Symbol & Description & Value & Source/constraint \\
\hline \multicolumn{4}{|c|}{ Nutrient transport and metabolism } \\
\hline$D_{\text {Gluc }}$ & Glucose diffusion coefficient & $1.05 \times 10^{-6} \mathrm{~cm}^{2} / \mathrm{s}$ & Casciari et al. (1992) \\
\hline$D_{O x}$ & Oxygen diffusion coefficient & $1.82 \times 10^{-5} \mathrm{~cm}^{2} / \mathrm{s}$ & Mueller-Klieser and Sutherland (1984) \\
\hline$D_{\text {Lac }}$ & Lactate diffusion coefficient & $1.78 \times 10^{-6} \mathrm{~cm}^{2} / \mathrm{s}$ & Casciari et al. (1992) \\
\hline$C_{G l u c}$ & Glucose concentration in the bulk & $5.5 \mathrm{mM}$ & Casciari et al. (1992) \\
\hline$C_{O x}$ & Oxygen concentration in the bulk & $0.21 \mathrm{mM}$ & Casciari et al. (1992) \\
\hline$C_{\text {Lac }}$ & Lactate concentration in the bulk & $0 \mathrm{mM}$ & Venkatasubramanian et al. (2006) \\
\hline$K_{G l u c}$ & Glucose uptake saturation constant & $4.0 \times 10^{-2} \mathrm{nM}$ & Casciari et al. (1992) \\
\hline$K_{O x}$ & Oxygen uptake saturation constant & $4.64 \times 10^{-3} \mathrm{mM}$ & Casciari et al. (1992) \\
\hline$K_{\text {Lac }}$ & Lactate uptake saturation constant & $5.65 \times 10^{-4} \mathrm{mM}$ & Venkatasubramanian et al. (2006) \\
\hline$Q_{G l u c}^{\max }$ & Maximum glucose uptake & $\begin{array}{l}1.33 \times 10^{-6} \mathrm{~mol} / \\
\text { cells }\end{array}$ & Casciari et al. (1992) \\
\hline$Q_{O x}^{\max }$ & Maximum oxygen uptake rate & $\begin{array}{l}7.16 \times 10^{-17} \mathrm{~mol} / \\
\text { cells }\end{array}$ & Casciari et al. (1992) \\
\hline$Q_{\text {Lac }}^{\max }$ & Maximum lactate uptake rate & $1.0 \times 10^{-14} \mathrm{~mol} / \mathrm{cells}$ & Venkatasubramanian et al. (2006) \\
\hline \multicolumn{4}{|c|}{ Cell-cycle phase related parameters } \\
\hline$\mu_{G 1, \max }^{G 0}$ & Maximum rate of transition from G1 to G0 phase & $4.0 \times 10^{-2} \mathrm{~h}^{-1}$ & Freyer and Schor (1989) \\
\hline$\mu_{G 0, \max }^{G 1}$ & Maximum rate of transition from $\mathrm{G} 1$ to $\mathrm{G} 0$ phase & $4.0 \times 10^{-2} h^{-1}$ & Fixed to be the same as $\mu_{G 1, \max }^{G 0}$ \\
\hline$\mu_{S, \max }^{G 1}$ & Maximum rate of transition from $\mathrm{G} 1$ to $\mathrm{S}$ phase & $1.2 \times 10^{-1} \mathrm{~h}^{-1}$ & Wibe et al. (1981) \\
\hline$\mu_{G 2, \max }^{S}$ & Maximum rate of transition from $S$ to $G 2$ phase & $1.08 \times 10^{-1} \mathrm{~h}^{-1}$ & Wibe et al. (1981) \\
\hline$\mu_{M, \max }^{G 2}$ & Maximum rate of transition from $\mathrm{G} 2$ to $\mathrm{M}$ phase & $4.6 \times 10^{-1} \mathrm{~h}^{-1}$ & Wibe et al. (1981) \\
\hline$\mu_{G 1, \max }^{M}$ & Maximum rate of transition from $\mathrm{M}$ to $\mathrm{G} 1$ phase & $9.8 \times 10^{-1} \mathrm{~h}^{-1}$ & Wibe et al. (1981) \\
\hline$K_{G 1, G 0}$ & Critical ATP production rate, G1-G0 transition & $\begin{array}{l}4.87 \times 10^{-16} \mathrm{~mol} / \\
\text { cells }\end{array}$ & (Freyer and Schor (1989) \\
\hline$K_{G 0, G 1}$ & Critical ATP production rate, G0-G1 transition & $\begin{array}{l}4.87 \times 10^{-16} \mathrm{~mol} / \\
\text { cells }\end{array}$ & Freyer and Schor (1989) \\
\hline$K_{G 1, S}$ & Critical ATP production rate, G1-S transition & $\begin{array}{l}6.20 \times 10^{-16} \mathrm{~mol} / \\
\text { cells }\end{array}$ & Larger than $K_{G 0, G 1}$ \\
\hline$K_{S, G 2}$ & Critical ATP production rate, $\mathrm{S}-\mathrm{G} 2$ transition & $\begin{array}{l}4.17 \times 10^{-16} \mathrm{~mol} / \\
\text { cells }\end{array}$ & Less than $K_{G 0, G 1}$ \\
\hline$K_{G 2, M}$ & Critical ATP production rate, G2-M transition & $\begin{array}{l}4.17 \times 10^{-16} \mathrm{~mol} / \\
\text { cells }\end{array}$ & Less than $K_{G 0, G 1}$ \\
\hline$K_{M, G 1}$ & Critical ATP production rate, $\mathrm{M}-\mathrm{G} 1$ transition & 0 & Mitosis assumed to be energy independent \\
\hline$\delta_{S}$ & Ratio of the volume of S phase cell to G1 phase cell & 1.52 & Tyson and Novak (2001) \\
\hline$\delta_{G 2}$ & Ratio of the volume of $\mathrm{G} 2$ phase cell to G1 phase cell & 1.72 & Tyson and Novak, (2001) \\
\hline & Ratio of the volume of $\mathrm{M}$ phase cell to $\mathrm{G} 1$ phase cell & 1.89 & Tyson and Novak (2001) \\
\hline$\delta_{G 0}$ & Ratio of the volume of G0 phase cell to G1 phase cell & 0.61 & Freyer and Schor (1989) \\
\hline
\end{tabular}

Death parameters due to nutrient deprivation

$\mu_{D, \max }^{i} \quad$ Maximum rate death from any living phase $i$ due to nutrient deprivation $14.2 \times 10^{-2} \mathrm{~h}^{-1}$

$K_{i, D} \quad$ Critical ATP production rate for $i$ th phase-D transition

$\delta_{D} \quad$ Ratio of the volume of initially formed dead cell to G1 phase cell

$6.96 \times 10^{-18} \mathrm{~mol} /$ cells

0.30

0.9

$\sigma \quad$ Basal survival rate

$\mu_{D, \text { volume }}^{\text {loss }} \quad$ Volume loss rate of dead cells

0.487

Drug related parameters

$D_{P A C} \quad$ Paclitaxel diffusion coefficient

$D_{5 F U} \quad$ 5-Fluorouracil diffusion coefficient

$\mu_{D, \max }^{P A C} \quad$ Maximum death rate of $\mathrm{G} 2$ and $\mathrm{M}$ phase cells due to paclitaxel

$K_{D}^{P A C} \quad$ Paclitaxel death rate saturation constant

$\mu_{D, \max }^{5 F U} \quad$ Maximum death rate of $\mathrm{S}$ cells due to 5-fluorouracil

$K_{D}^{5 F U} \quad$ S-phase specific death rate saturation constant for 5-fluorouracil

$\mu_{D, C C N S \text {,max }}^{5 F U}$ Cell-cycle phase non-specific death rate due to 5-fluorouracil

$K_{D, C C N S}^{P A C} \quad$ Cell-cycle phase non-specific death rate saturation constant for 5fluorouracil

$1.1 \times 10^{-9} \mathrm{~cm}^{2} / \mathrm{s}$
$6.05 \times 10^{-8} \mathrm{~cm}^{2} / \mathrm{s}$
$3.3 \times 10^{-1} \mathrm{~h}^{-1}$
$6.225 \mathrm{nM}$
$7.76 \times 10^{-2} \mathrm{~h}^{-1}$
$0.1 \mu \mathrm{M}$
$4.6 \times 10^{-1} \mathrm{~h}^{-1}$
$503.9 \mu \mathrm{M}$

$1.1 \times 10^{-9} \mathrm{~cm}^{2} / \mathrm{s}$ $6.05 \times 10^{-8} \mathrm{~cm}^{2} / \mathrm{s}$
$3.3 \times 10^{-1} \mathrm{~h}^{-1}$ $6.225 \mathrm{nM}$

$7.76 \times 10^{-2} \mathrm{~h}^{-1}$ $4.6 \times 10^{-1} \mathrm{~h}^{-1}$ $503.9 \mu \mathrm{M}$
Venkatasubramanian et al. (2006)

Venkatasubramanian et al. (2006)

Venkatasubramanian et al. (2006)

Ward and King (1997)

Fixed so as to obtain a saturated size of $1 \mathrm{~mm}$

Nicholson et al. (1997)

Tunggal et al. (1999)

Au et al. (1998)

Au et al. (1998)

Kufe and Major (1981), Ueda et al. (1997)

Kufe and Major (1981), Ueda et al. (1997)

Kufe and Major (1981), Ueda et al. (1997)

Kufe and Major (1981), Ueda et al. (1997)

Pharmacokinetic parameters

Paclitaxel

$d_{P A C} \quad$ Paclitaxel dosage concentration

$k_{21} \quad$ First-order rate constant for return from 2nd to 1st compartment

$69.3 \mu \mathrm{M}$

$1.4 \mathrm{~h}^{-1}$
Gianni et al. (1995)

Gianni et al. (1995) 
Table 2 (continued)

\begin{tabular}{|c|c|c|c|}
\hline Symbol & Description & Value & Source/constraint \\
\hline$V_{m}$ & Maximum transport rate from the 1 st to the 2 nd compartment & $17.7 \mu \mathrm{M} / \mathrm{h}$ & Gianni et al. (1995) \\
\hline$K_{m}$ & Transport saturation constant from the 1 st to 2 nd compartment & $0.23 \mu \mathrm{M}$ & Gianni et al. (1995) \\
\hline$V_{m}^{O}$ & Maximum clearance rate of paclitaxel from the 1 st compartment & $29.9 \mu \mathrm{M} / \mathrm{h}$ & Gianni et al. (1995) \\
\hline$K_{m}^{O}$ & Clearance saturation constant from the 1st compartment & $7.0 \mu \mathrm{M}$ & Gianni et al. (1995) \\
\hline$V_{m}^{m}$ & Maximum metabolism rate from the 1 st compartment & $1.61 \mu \mathrm{M} / \mathrm{h}$ & Gianni et al. (1995) \\
\hline$K_{m}^{m}$ & Metabolism rate saturation constant from the 1 st compartment & $60.4 \mu \mathrm{M}$ & Gianni et al. (1995) \\
\hline$k_{13}$ & First-order transport rate constant from 1 st to 3 rd compartment & $2.6 \mathrm{~h}^{-1}$ & Gianni et al. (1995) \\
\hline$k_{31}$ & First-order transport rate constant from 3 rd to 1 st compartment & $0.6 \mathrm{~h}^{-1}$ & Gianni et al. (1995) \\
\hline \multicolumn{4}{|l|}{$5 F U$} \\
\hline$d_{5 F U}$ & 5-Fluorouracil dosage concentration & $2.16 \mathrm{mM}$ & Terret et al. (2000) \\
\hline$V_{m}$ & Maximum clearance rate of from the 1 st compartment. & $1260 \mathrm{mg} / \mathrm{h}$ & Terret et al. (2000) \\
\hline$K_{m}$ & Clearance rate saturation constant from the 1 st compartment & $6.05 \mathrm{mg} / \mathrm{L}$ & Terret et al. (2000) \\
\hline$k_{12}$ & First-order transport rate constant from 1 st to 2 nd compartment & $5.35 \mathrm{~h}^{-1}$ & Terret et al. (2000) \\
\hline$k_{21}$ & First-order transport rate constant from 2 nd to 1 st compartment & $5.69 \mathrm{~h}^{-1}$ & Terret et al. (2000) \\
\hline
\end{tabular}

an empirical method used to describe the clearance of drug from the body by absorption, metabolic degradation, and excretion. The pharmacokinetics of 5FU and paclitaxel were determined in clinical trials to best fit standard twoand three-compartment models, respectively (Gianni et al., 1995; Terret et al., 2000). In these models the central compartment describes the blood plasma which is assumed to be well mixed. The peripheral compartments have slower distribution and include organs and tissues that are poorly perfused. Here, the drug concentration at the periphery of the tumor is equivalent to the plasma concentration, which is given by the concentration in the central compartment.

The pharmacokinetic of paclitaxel was found to fit best to a three-compartment model (Gianni et al., 1995) with a central compartment containing the tumor and two peripheral compartments (Fig. 2a). Drug exchange between the first and second compartments was first-order and linear, while exchange between the first and third components was nonlinear and saturable according to Michaelis-Menten kinetics. Paclitaxel was eliminated from the system by two mechanisms: a nonlinear, saturable clearance mechanism and irreversible, nonlinear metabolism into 6- $\alpha$-hydroxypaclitaxel (Gianni et al., 1995). These exchanges and degradations were modeled with a set of ordinary differential equations:

$$
\begin{aligned}
\frac{d C_{1}}{d t}= & k_{31} C_{3}-k_{13} C_{1}+k_{21} C_{2}-\frac{V_{m} C_{1}}{K_{m}+C_{1}}-\frac{V_{m}^{O} C_{1}}{K_{m}^{O}+C_{1}} \\
& -\frac{V_{m}^{m} C_{1}}{K_{m}^{m}+C_{1}}+\frac{d_{P A C}}{t_{\text {pulse }}}\left[H(t)-H\left(t-t_{\text {pulse }}\right)\right] \\
\frac{d C_{2}}{d t}= & \frac{V_{m} C_{1}}{K_{m}+C_{1}}-k_{21} C_{2} \\
\frac{d C_{3}}{d t}= & k_{13} C_{1}-k_{31} C_{3} \\
H(t)= & \begin{cases}0 & \text { for } t<0 \\
1 & \text { for } t>0\end{cases}
\end{aligned}
$$
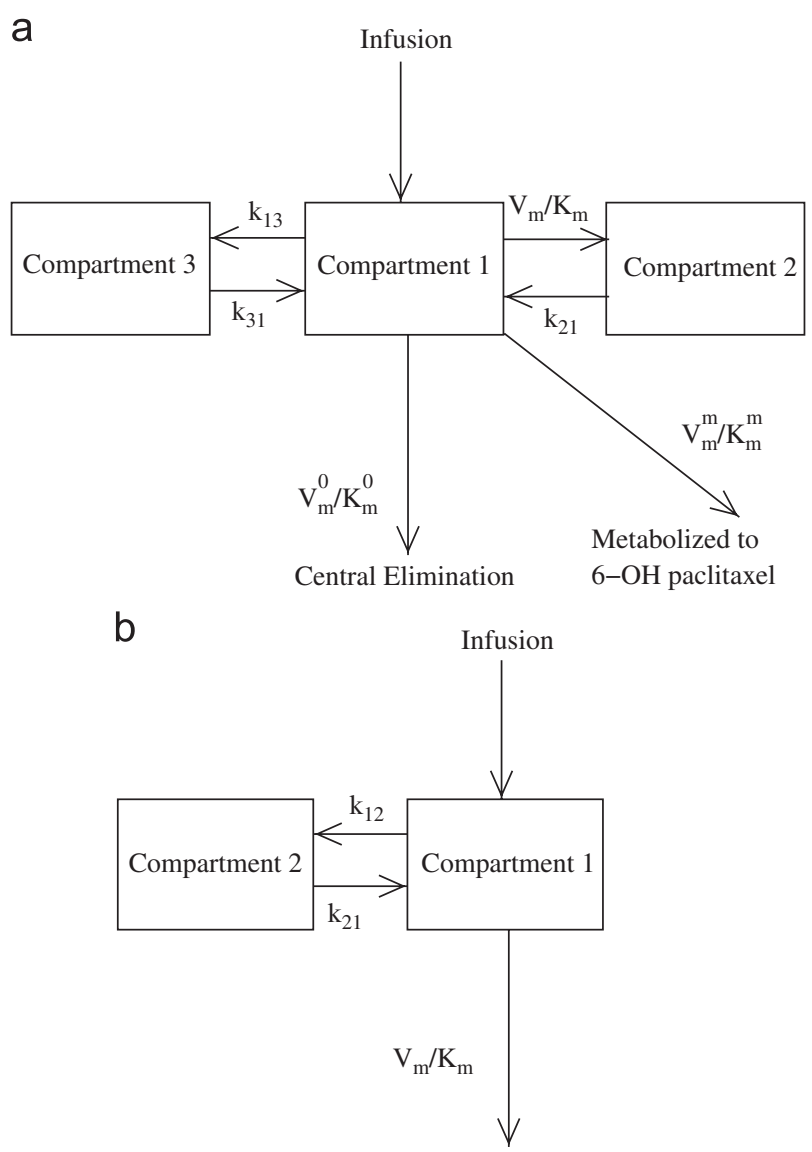

Fig. 2. Multi-compartment pharmacokinetic models for (a) paclitaxel and (b) 5-fluorouracil. (a) In the three-compartment model for paclitaxel exchange between the first and second compartments is first order and linear, and exchange between the first and third components follows Michaelis-Menten kinetics. Paclitaxel is eliminated from the system by nonlinear clearance and nonlinear metabolism into 6- $\alpha$-hydroxypaclitaxel. (b) In the two compartment model for 5-fluorouracil exchange between the two compartments is first-order and linear and clearance follows Michaelis-Menten kinetics.

where $H(t)$ is the unit step function switching at time $t=0$ and $d_{P A C}$ is the dosage concentration of the administered drug. The drug concentrations in the first, second and third 
compartments are $C_{1}, C_{2}$, and $C_{3}$ respectively; the first-order rate constants for exchange between the first, second, and third compartments are $k_{12}, k_{31}$, and $k_{13}$. The Michaelis-Menten rate constants for the transfer from the first to the third compartment, the clearance by the kidneys, and metabolism into 6- $\alpha$ hydroxypaclitaxel are $V_{m}$ and $K_{m}, V_{m}^{O}$ and $K_{m}^{O}$, and $V_{m}^{m}$ and $K_{m}^{m}$, respectively.

The pharmacokinetics of 5FU was previously found to best fit a two compartmental model (Fig. 2b) with constant linear rates of exchange between the compartments and a nonlinear saturable rate of elimination (Terret et al., 2000):

$\frac{d C_{1}}{d t}=k_{21} C_{2}-k_{12} C_{1}-\frac{V_{m} C_{1}}{K_{m}+C_{1}}+\frac{d_{5 F U}}{t_{p u l s e}}\left[H(t)-H\left(t-t_{p u l s e}\right)\right]$

$\frac{d C_{2}}{d t}=k_{12} C_{1}-k_{21} C_{2}$

For both drugs the concentration at the tumor periphery was given by the concentration in the central compartment:

$\left.C_{j}(t)\right|_{r=R}=C_{1}(t)$

\subsection{Drug cytotoxicity}

The cytotoxic effects of paclitaxel and 5FU on cells were modeled using Monod-type functions. These two drugs affect cells in different cell-cycle phases. Paclitaxel is cytotoxic to cells in $\mathrm{G} 2$ and $\mathrm{M}$ phases, and $5 \mathrm{FU}$ is $\mathrm{S}$ phase specific at low concentrations and cell-cycle-phase non-specific (CCNS) at higher concentrations. At low concentrations 5FU intercalates into DNA, and at high concentrations it misincorporates into RNA (Tanaka et al., 2000). The effects of drug-induced death were assumed to be additive to the metabolic rates, which was implemented by adding terms to the cell-cycle phase expressions in Eq. (1).

$g_{G 1}^{\text {drug }}=g_{G 1}-\mu_{D, C N S}^{5 F U} n_{G 1}$

$g_{S}^{d r u g}=g_{S}-\mu_{D}^{5 F U} n_{S}-\mu_{D, C N S}^{5 F U} n_{S}$

$g_{G 2}^{d r u g}=g_{G 2}-\mu_{D}^{P A C} n_{G 2}-\mu_{D, C N S}^{5 F U} n_{G 2}$

$g_{M}^{\text {drug }}=g_{M}-\mu_{D}^{P A C} n_{M}-\mu_{D, C N S}^{5 F U} n_{M}$

$\mu_{D}^{P A C}=\frac{\mu_{D, \text { max }}^{P A C} C_{P A C}}{K_{D}^{P A C}+C_{P A C}} \quad \mu_{D}^{5 F U}=\frac{\mu_{D, \text { max }}^{5 F U} C_{5 F U}}{K_{D}^{5 F U}+C_{5 F U}}$

$\mu_{D, C N S}^{5 F U}=\frac{\mu_{D, C N S, \max }^{5 F U} C_{5 F U}}{K_{D, C N S}^{5 F U}+C_{5 F U}}$

In Eqs. (23) and (24), $\mu_{D}^{P A C}, \mu_{D}^{5 F U}$, and $\mu_{D, C C N S}^{5 F U}$ are the rates of death of $\mathrm{G} 2 / \mathrm{M}$-phase cells due to paclitaxel, $\mathrm{S}$ phase cells due to 5FU, and cell-cycle non-specific death due to $5 \mathrm{FU}$, respectively. The effect of each drug was investigated individually during the simulations.

\section{Parameter estimation}

The parameters used in the model (Table 2) were obtained in three ways: (1) they were extracted directly from the literature, (2) they were calculated from experimental data in the literature, or (3) they were estimated based on known physiological behavior. The pharmacokinetic parameters for paclitaxel and 5FU (Table 2) were obtained from human trials as reported by Gianni et al. (1995) and Terret et al. (2000), respectively. The volume of dead cells $\left(V_{D}\right)$ was assumed to be $50 \%$ of the quiescent cell volume $\left(V_{G 0}\right)$, and the rate of volume loss $\left(\mu_{D, \text { loss }}\right)$ was manually adjusted to produce a saturated spheroid with a radius of $1 \mathrm{~mm}$.

\subsection{Estimation of cell-cycle parameters}

The maximum transition rates $\left(\mu_{t o, \text { max }}^{\text {from }}\right)$ between the proliferating cell-cycle phases were estimated from the length of time cells spend in each phase during exponential growth in monolayer culture. Wibe et al. found that transition times for each phase were $T_{G 1}=7.9, T_{S}=7$, $T_{G 2}=2.1$ and $T_{M}=1 \mathrm{~h}$ (Wibe et al., 1981). The fraction of cells in each phase $\left(g_{1}, s, g_{2}\right.$, and $\left.m\right)$ were calculated from the transition times using Steel's formula (Montalenti et al., 1998):

$$
\begin{aligned}
m & =2^{\left(T_{M} / T_{D}\right)}-1 \\
g_{2} & =2^{\left(\left(T_{M}+T_{G 2}\right) / T_{D}\right)}-1-m \\
s & =2^{\left(\left(T_{M}+T_{G 2}+T_{S}\right) / T_{D}\right)}-1-m-g_{2} \\
g_{1} & =1-m-g_{2}-s
\end{aligned}
$$

The maximal transition rates were estimated from the cell-cycle-phase balances, the phase fractions, and the average doubling time $\left(T_{D}\right)$ assuming that the fraction of cells in each cell-cycle phase reached steady state in exponentially growing monolayer cultures:

$$
\begin{gathered}
{\left[\begin{array}{c}
d g_{1} / d t \\
d s / d t \\
d g_{2} / d t \\
0
\end{array}\right]-\left[\begin{array}{cccc}
-g_{1} & 0 & 0 & 2 m \\
g_{1} & -s & 0 & 0 \\
0 & s & -g_{2} & 0 \\
0 & 0 & 0 & m
\end{array}\right]\left[\begin{array}{l}
\mu_{S, \text { max }}^{G 1} \\
\mu_{G 2, \max }^{S} \\
\mu_{M, \max }^{G 2} \\
\mu_{G 1, \max }^{M}
\end{array}\right]} \\
+\mu_{G 1, \text { max }}^{M} m\left[\begin{array}{c}
g_{1} \\
s \\
g_{2} \\
0
\end{array}\right]=\left[\begin{array}{c}
0 \\
0 \\
0 \\
-\frac{\ln (2)}{T_{D}}
\end{array}\right]
\end{gathered}
$$


At steady state $d g_{1} / d t=d s / d t=d g_{2} / d t=0$ :

$\left[\begin{array}{c}\mu_{S, \text { max }}^{G 1} \\ \mu_{G 2, \max }^{S} \\ \mu_{M, \text { max }}^{G 2} \\ \mu_{G 1, \text { max }}^{M}\end{array}\right]=\left[\begin{array}{cccc}-g_{1} & 0 & 0 & 2 m-m g_{1} \\ g_{1} & -S & 0 & -m s \\ 0 & s & -g_{2} & -m g_{2} \\ 0 & 0 & 0 & m / \ln (2)\end{array}\right]^{-1}\left[\begin{array}{c}0 \\ 0 \\ 0 \\ \frac{1}{T_{D}}\end{array}\right]$

The maximum transition rate from G0 to G1 $\left(\mu_{G 1, \max }^{G 0}\right)$ was estimated from spheroid dissociation experiments (Freyer and Schor, 1989), where quiescent cells were dissociated from the interior of spheroids and grown in monolayers adequately supplied with nutrients. Compared to proliferating cells, quiescent cells experienced a lag period $\left(T_{\text {Lag }}=25 \mathrm{~h}\right)$ before growing exponentially (Freyer and Schor, 1989). If the inner spheroid region was assumed to be entirely composed of quiescent cells, the length of this lag was dependant on the transition rate from G0 to G1.

$\mu_{G 0, \text { max }}^{G 1}=\ln (2) / T_{D} \frac{2^{-T_{L a g} / T_{D}}}{1-2^{-T_{L a g} / T_{D}}}$

No experiments could be found in the literature that study the maximum transition rate from G1 to G0 $\left(\mu_{G 0, \max }^{G 1}\right)$, so this parameter could not be calculated. This rate was assumed to be equivalent to the maximum transition rate from $\mathrm{G} 0$ to $\mathrm{G} 1$, which is reasonable because both transitions require the expression and inhibition of similar cell-cycle genes.

The transition rates between each phase were described with Monod-type kinetics. Saturable, hyperbolic expressions were used because each rate must have a maximum value $\left(\mu_{t o, \text { max }}^{\text {from }}\right)$ but diminish to zero at low ATP production rates. Little is known about the saturation constants $\left(K_{\text {from,to }}\right)$, but their relative values and their orders of magnitude could be estimated (Table 2). M phase was assumed to be short and not controlled by energy availability $\left(K_{M, G 1}=0\right)$. At intermediate energy availability, the G1 phase was assumed to elongate (Rossow et al., 1979), i.e. cells could not continue around the cycle, but also not become quiescent $\left(K_{G 1, S}>K_{G 1, G 0}\right)$. Once entering the cell cycle, cells would continue their progression with reduced dependence on energy availability $\left(K_{S, G 2}>K_{G 1, G 0}\right)$. Together these assumptions produce the relation, $K_{S, G 2}<K_{G 1, G 0}<K_{G 1, S}$. Finally, the saturation constant for the transition from G1 to G0 $\left(K_{G 1, G 0}\right)$ was estimated to match the percentage of quiescent cells previously observed in spheroids (Freyer and Schor, 1989) and the remaining saturation constants $\left(K_{G 1, S}\right.$ and $\left.K_{S, G 2}\right)$ were adjusted in accordance to the above relation. The cell volume in each phase was estimated by assuming that cell volume increases linearly throughout the cycle (Tyson and Novak, 2001). The volume of G0 cells was obtained from Freyer and Sutherland (Freyer and Sutherland, 1980).

\subsection{Drug diffusivity}

Drug transport was modeled using effective diffusion coefficients that represent the combined effects of extracellular diffusion and transmembrane transport. The diffusion of anti-cancer drugs is also known to be affected by intracellular binding and degradation (Lankelma et al., 2000). Detailed models have been developed that account for these effects, but their accuracy depends on estimation of many unknown parameters (Kuh et al., 1999, 2000; Lankelma et al., 2000). The effective diffusion coefficients used in this model were estimated using data extracted from multi-cellular layer experiments, in which a layer of cells is grown on a collagen coated Teflon membrane between two compartments (Grantab et al., 2006; Nicholson et al., 1997; Tannock et al., 2002; Tunggal et al., 1999). A known amount of drug is added to one compartment and the concentration is measured in both compartments as a function of time. The following equations were used to fit these data.

$$
\begin{aligned}
\frac{d C_{A}}{d t} & =\left.\frac{A D_{\text {cell }}\left(C_{A}-C_{\text {int }}\right)}{V_{A} L_{\text {cell }}} \quad C_{A}\right|_{t=0}=C_{A 0} \\
\frac{d C_{B}}{d t} & =\left.\frac{A K_{\text {mem }}\left(C_{\text {int }}-C_{B}\right)}{V_{B}} \quad C_{B}\right|_{t=0}=0 \\
C_{\text {int }} & =\frac{K_{\text {mem }} C_{B}+\left(D_{\text {cell }} / L_{\text {cell }}\right) C_{A}}{K_{\text {mem }}+\left(D_{\text {cell }} / L_{\text {cell }}\right)}
\end{aligned}
$$

The drug concentrations and volumes of the two compartments are $C_{A}, C_{B}, V_{A}$, and $V_{B}$. The compartments were assumed to be well mixed and the diffusion resistances were ascribed to be the multi-cellular layer and the Teflon membrane. Additional parameters in Eq. (29) are $D_{\text {cell }}$, the effective diffusion coefficient; $L_{\text {cell }}$, the width of the multi-cellular layer; $K_{m e m}$, the mass transfer coefficient of the membrane; $A$, the cross-sectional area; and $C_{i n t}$, the concentration at the interface of the multicellular layer and the membrane. Data from experiments performed on Teflon membrane without multi-cellular layers were used to estimate the parameter, $K_{m e m}$ which describes the resistance solely due to membrane. This parameter was used further to fit to the remaining experimental data in order to estimate the parameter describing the resistance due to the multi-cellular layer $\left(D_{\text {cell }}\right)$. Because the diffusivity of paclitaxel may be cell-type dependent (Nicholson et al., 1997; Tannock et al., 2002), the effect of a broad range diffusivities was investigated.

\subsection{Drug cytotoxicity parameters}

The rate parameters for drug-induced cell death $\left(\mu_{D, \max }^{\text {drug }}\right.$ and $\left.K_{D}^{d r u g}\right)$ were estimated from dose-escalation experiments for paclitaxel (Zhao et al., 2005) and 5FU (Tanaka et al., 2000), where monolayers of cells were exposed to increasing concentrations of drug and the surviving 


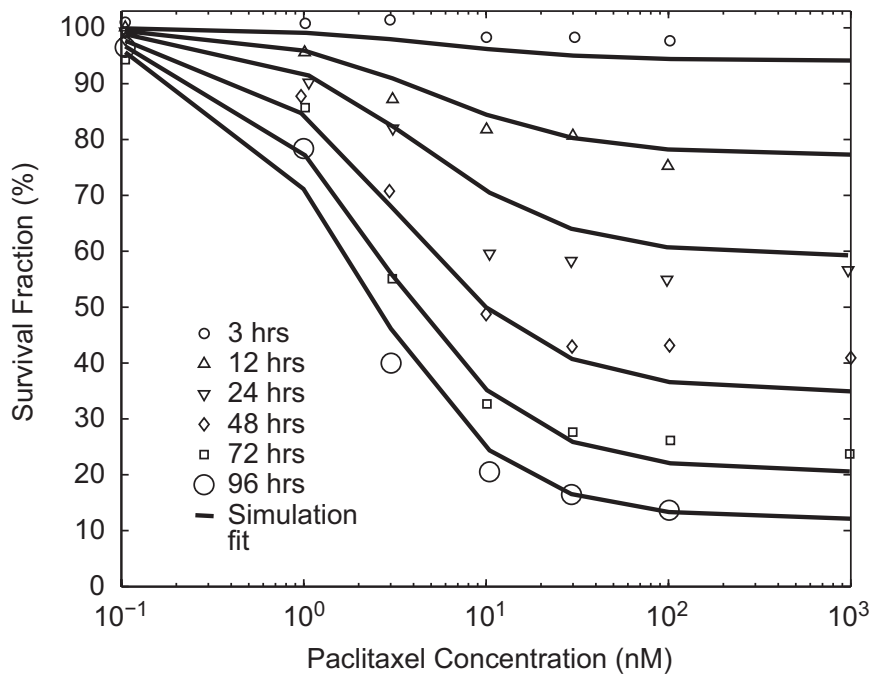

Fig. 3. Paclitaxel monolayer dose escalation data and simulation results from death rate parameter estimation. Survival fraction is the fraction of living cells after treatment with drug (of a particular concentration for a specific exposure time), compared to the number of living cells in the absence of drug.

fraction was measured as a function of time (Fig. 3). A monolayer of cells was simulated by eliminating all transport terms from the model, which included Eqs. (2), (3), (5), (6) and the local velocity term in Eq. (1). The concentrations of nutrients were assumed to be constantly high, which caused cells to pass through the cell-cycle at the maximum rates. The rates of drug-induced cell death were assumed to be dependant on the extra-cellular drug concentration according to Eq. (23). As described above, paclitaxel was assumed to be toxic only to G2 and M-phase cells (Zhao et al., 2005) and 5FU was assumed to be toxic to $\mathrm{S}$ phase cells at low concentrations and all cells at high concentrations (Tanaka et al., 2000). Drug-induced cell death parameters were estimated using the constrained optimization function fmincon (Matlab 7.0) by minimizing the mean square error between the survival fractions in experiment and simulation.

Survival fractions were reported for paclitaxel concentrations ranging from $0.01 \mathrm{nM}$ to $10 \mu \mathrm{M}$ and for exposure times from 3 to $96 \mathrm{~h}$ (Au et al., 1998; reported in Fig. 3). The dose-response curves obtained using the model, fit well to these reported values (Fig. 3). Consistent with experiments, a plateau was observed in the survival fraction at high drug concentrations and the survival fractions at this plateau decreased with exposure time (Au et al., 1998). The model nicely fit similar survival fraction data for $5 \mathrm{FU}$ (Tanaka et al., 2000).

\subsection{Numerical solution}

The tumor model consisted of a coupled set of nonlinear partial differential, ordinary differential, and algebraic equations with a free outer boundary. All equations were non-dimensionalized to improve problem scaling. The following non-dimensional variables were used:

$$
\begin{aligned}
& \hat{t}=t / T_{d}, \quad \hat{r}=r / R \quad \hat{v}=v /\left(R / T_{D}\right) \\
& R(0)=\left(3 V_{G 1} / 4 \pi\right)^{1 / 3}, \quad \widehat{\mu}_{\text {from }}^{t o}=\mu_{\text {from }}^{t o} /\left(1 / T_{D}\right) \\
& \widehat{C}_{g l u c}=C_{\text {gluc }} / C_{\text {gluc }, \text { bulk }}, \quad \widehat{C}_{\text {lac }}=C_{\text {lac }} / C_{\text {lac,bulk }} \\
& \widehat{C}_{o x}=C_{o x} / c_{o x, b u l k}, \quad \widehat{C}_{d 1}=C_{d 1} / C_{d 1, \text { criti }} \\
& \hat{n}_{i}=n_{i} /\left(1 / V_{i}\right)
\end{aligned}
$$

The original model was reduced to a set of algebraic equations and ordinary differential equations in time by spatial discretization using the method of orthogonal collocation on finite elements. At each time point, the spatial domain was mapped to a domain of unit length using a moving grid scheme. The local velocity of the tumor perimeter, $v(R)$, was assigned to the outermost grid point to maintain a moving boundary (Crank, 1984). A unique velocity was assigned to each interior grid point to ensure that it remained stationary with respect to the outermost point:

$\left(\begin{array}{c}\partial \hat{\theta} \\ \frac{j}{\partial \hat{t}}\end{array}\right)_{j}=\widehat{v}_{j}^{\text {grid }} \frac{\partial \hat{\theta}}{\partial \hat{r}}+\left(\begin{array}{c}\partial \widehat{\theta} \\ \frac{j}{\partial \hat{t}}\end{array}\right)_{\widehat{r}} \widehat{v}_{j}^{\text {grid }}=\widehat{r}_{j} \widehat{v}(R(\hat{t}))$

Here $\widehat{\theta}$ corresponds to the dimensionless number densities for each cell-cycle phase and to the dimensionless drug concentration in the spheroid at grid point $j$.

The grid point locations were generated by dividing the unit domain into equispaced finite elements and selecting a finite number of grid points within each element as roots of the appropriate Jacobi polynomial (Finlayson, 1980). First the unit domain was divided into 20 finite elements, each containing three internal collocation points. A finer grid was implemented at the tumor periphery to capture steep drug concentration profiles typically observed for slow diffusing drugs. In particular, the last peripheral element was further divided into five smaller elements, each with three internal collocation points.

The discretized equations were solved simultaneously using the differential-algebraic equation (DAE) solver DASPK 2.0 (Brown et al., 1994, 1995). DASPK options were used to exploit the considerable sparsity of the Jacobian matrix and to calculate a consistent set of initial conditions for the DAE system. A constant time step, $\Delta t=0.005$ days, was used for all simulations.

\section{Results and discussion}

\subsection{Cell-cycle phases in spheroids}

The cell-cycle phase distribution in the different regions of a spheroid was simulated to test the validity of the model. Spheroid growth was initiated with a spherical tissue mass the size of a single cell and progressed in the absence of drug. Growth was characterized by a slow exponential phase followed by a linear growth phase, and terminated with 
a

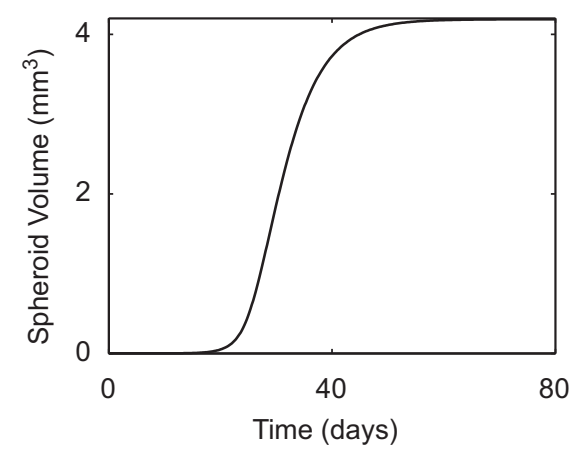

C

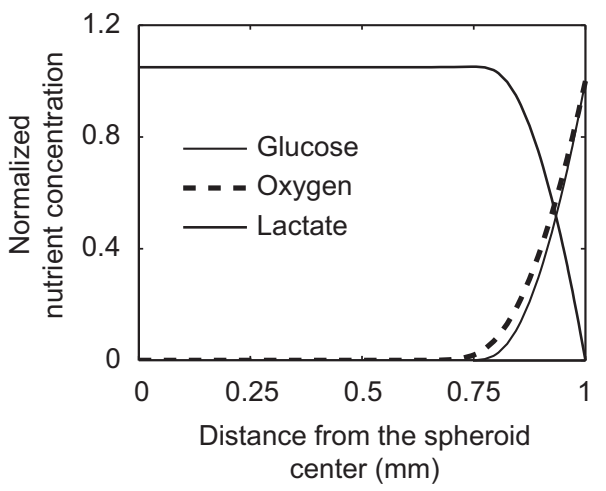

b

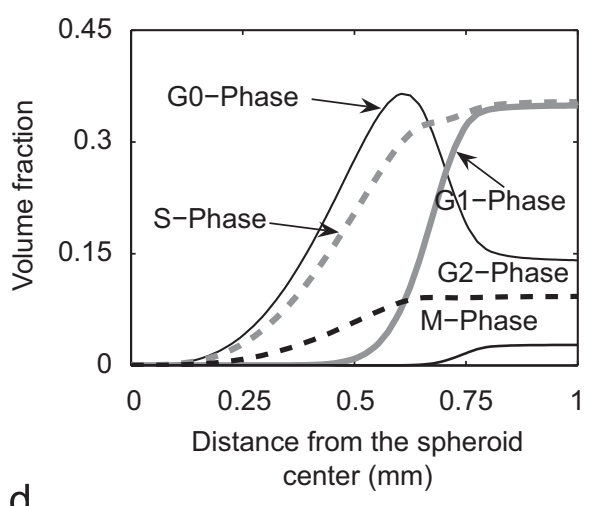

d

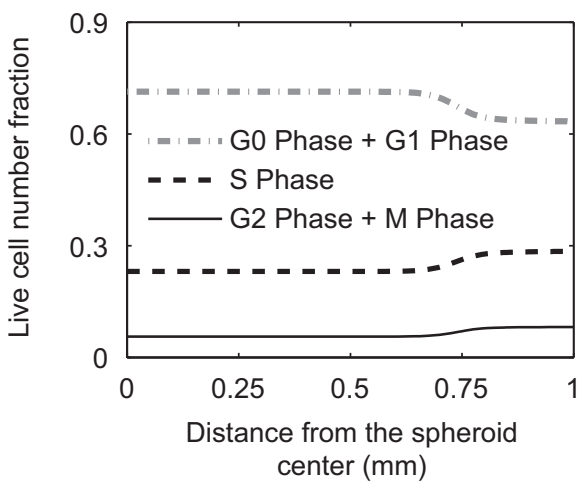

Fig. 4. Spheroid growth and saturation in the absence of a drug. (a) Growth simulation from a single cell in G1 phase to a saturated spheroid of 1 mm radius. Spheroid volume initially exhibits an exponential increase, followed by a linear increase, and finally reaching a saturated steady state. (b) Cell-cycle phase volume fractions in a saturated spheroid. More cells are present in the quiescent G0 phase towards the spheroid center. (c) Nutrient profiles of key nutrients, glucose, and oxygen. Glucose and oxygen are only available till 250-300 $\mu \mathrm{m}$ from the spheroid periphery, and lactate is present throughout. Lactate is not consumed in the interior because of the lack of oxygen. (d) Cell-cycle-phase fractions of live cells as a function of distance from the spheroid center. This simulation result is qualitatively similar to experimental data reported by Freyer (1998).

Table 3

Fraction of cells in different cell-cycle phases of monolayer cultures and spheroids at 10 th day, 30 th day and at saturation

\begin{tabular}{llll}
\hline & $\begin{array}{l}\text { Spheroid at } \\
T=10 \text { days }\end{array}$ & $\begin{array}{l}\text { Spheroid at } \\
T=30 \text { days }\end{array}$ & $\begin{array}{l}\text { Saturated } \\
\text { spheroid }\end{array}$ \\
\hline G0 phase fraction & 0.14 & 0.19 & 0.195 \\
G1 phase fraction & 0.35 & 0.27 & 0.24 \\
S phase fraction & 0.35 & 0.325 & 0.3 \\
G2 phase fraction & 0.09 & 0.085 & 0.08 \\
M phase fraction & 0.025 & 0.02 & 0.015
\end{tabular}

As the spheroid grows, a slow and gradual increase in the fraction of cells in the quiescent G0 phase is accompanied by a corresponding decrease in G1, S, G2 and M phase cells.

a saturated spheroid with a radius of $1 \mathrm{~mm}$ (Fig. 4a). These growth phases are consistent with spheroid growth experiments (Durand, 1990), and can be explained by investigating local growth rates and nutrient concentrations. When the spheroid was small, all cells were exposed to high nutrient concentrations and grew at their maximum exponential rate. As the spheroid grew larger, nutrient limitations appeared in the spheroid core causing growth cessation and death. The tradeoff between growth at the periphery and death in the center resulted in linear growth. As the spheroid grew even larger, degradation of necrotic debris in the center balanced volume generation at the periphery, and the growth of the spheroid saturated (Fig. 4a).

In the small spheroid there were no spatial variations in the distribution of cells in the cell-cycle phases, and the fractions of cells in each phase were equivalent to the fractions present in monolayer cultures. As the spheroid grew, the overall cell population became more quiescent as the fraction of cells in $\mathrm{G} 0$ increased and the fraction of cells in the proliferating phases $(\mathrm{G} 1, \mathrm{~S}, \mathrm{G} 2$, and $\mathrm{M})$ decreased (Table 3).

In the saturated spheroid, the fraction of cells in each phase was dependent on the radius (Fig. 4b) because of nutrient gradients (Fig. 4c). Glucose and oxygen were only present in a region approximately $250 \mu \mathrm{m}$ from the spheroid edge and the lactate concentration increased towards the interior (Fig. 4c). These nutrient gradients created three distinct regions: a peripheral region where cells traversed the cell-cycle phases at the maximum rates, an intermediate region where the rates between the phases were affected by available energy, and a central region where the cell cycle stopped and cells in all phases died (Fig. 4b, c). 
In the peripheral region of the saturated spheroid, the fraction of cells in each cell-cycle phase was constant and equal to the fraction in monolayer cultures (Fig. $4 \mathrm{~b}$ ). In the transition region, cells in $\mathrm{G} 1$ began to enter $\mathrm{G} 0$ (Fig. 4b). In this region, cells stalled in G1, resulting in a slight decrease in the $\mathrm{S}$ phase fraction (Fig. 4b). Cells also stalled in S and G2, which completely eliminated M-phase cells $350 \mu \mathrm{m}$ from the exterior, because the transition to $\mathrm{G} 1$ from $\mathrm{M}$ is independent of nutrient availability. The transition of cells from G1 to G0 resulted in the complete absence of $\mathrm{G} 1$ cells beyond $600 \mu \mathrm{m}$ from the spheroid edge. Cells in G0 increased towards a maximum in the intermediate region and decreased beyond $400 \mu \mathrm{m}$ as the rate of death surpassed the transition rate from G1. In the central region, cells in all the remaining phases (G0, S, and G2) died because of severe nutrient limitations.

These transitions match measured cell-cycle fraction in spheroids (Freyer and Sutherland, 1980) showing that the fraction of live cells in $\mathrm{G} 0 / \mathrm{G} 1$ increased and the fraction of live cells in $\mathrm{S}$ and $\mathrm{G} 2 / \mathrm{M}$ decreased towards the center. Wibe et al. (1981) identified cells that were stalled in S, G2, and $\mathrm{G} 0$ in the core of spheroids. Our simulation results were qualitatively consistent with these observations (Fig. 4d).

\subsection{Drug effects on spheroid growth}

Simulations of spheroid cultures were useful because they gave the theoretical limits of drug treatment by eliminating the effects of pharmacokinetics. In addition, predicted drug effects could easily be validated in the laboratory. The effect of drug treatment on saturated spheroids was simulated to determine the critical drug concentration necessary for complete tumor clearance and to compare the relative effects of dosage and exposure time. In physical spheroid experiments, drug concentrations cannot be changed as a function of time, but only in a step-wise fashion by replacing culture medium. Spheroid cultures were simulated by eliminating all pharmacokinetic terms and holding the drug concentration at the periphery $\left(C_{j}\right)$ constant for a fixed period of time $\left(t_{\text {pulse }}\right)$ in Eq. (19).

When spheroids were exposed to fixed concentrations of paclitaxel $(1,5,10$, and $50 \mathrm{nM})$, one of two different behaviors were observed: (1) spheroids shrank slightly and saturated at a smaller size or (2) spheroids were completely eliminated (Fig. 5a). In these simulations, drug diffusion limitations were only present at early times and all regions were exposed to almost constant drug concentrations thereafter. At low drug concentrations $(\leqslant 1 \mathrm{nM})$, death due to drug exposure was balanced by cell growth, which resulted in stabilization at a smaller spheroid radius (Fig. 5a). At higher concentrations $(\geqslant 5 \mathrm{nM})$, the rate of death due to drug exposure was close to its maximum value $\left(\mu_{D, \max }^{P A C}\right)$. At this rate, death overpowered growth and the spheroids shrank until they

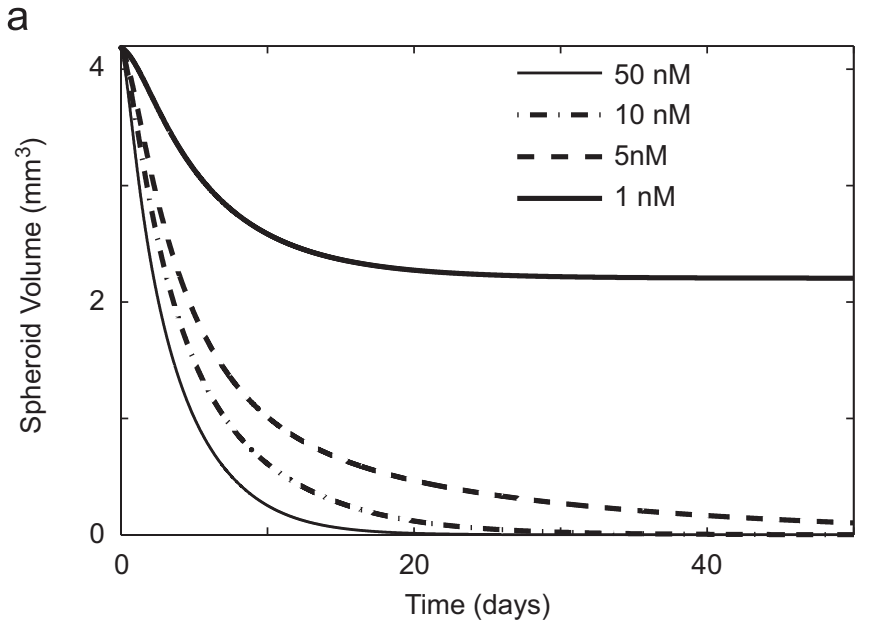

b

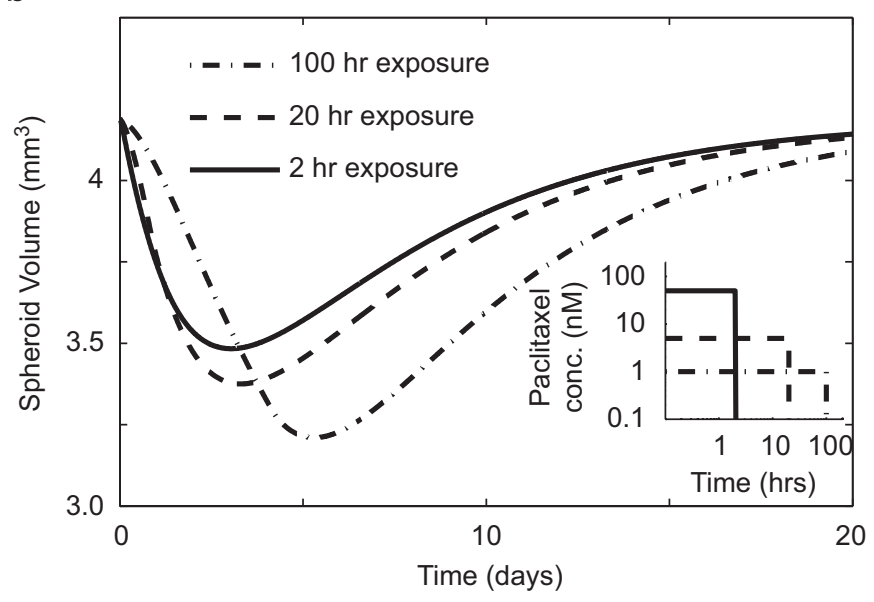

Fig. 5. Effect of drug exposure on spheroids. (a) Drug response of spheroids exposed to a constant paclitaxel concentration. Spheroids were completely eliminated when exposed to concentrations greater that $1.6 \mathrm{nM}$. (b) Comparison of concentration and exposure times on spheroid growth for a fixed area under the curve (AUC) of $0.09 \mu \mathrm{molh}$. Longer exposure and lower concentrations had a greater effect on spheroid volume.

disappeared completely (Fig. 5a). The critical concentration of paclitaxel that enables complete elimination of the spheroid was $1.6 \mathrm{nM}$. This concentration is close to the $\mathrm{IC}_{50}$ of $2 \mathrm{nM}$, which is the concentration that kills $50 \%$ of cells grown in monolayer cultures after $96 \mathrm{~h}$ (Au et al., 1998). Knowledge of this theoretical limit is useful because if an average concentration of $1.6 \mathrm{nM}$ is not maintained throughout a tumor, it is impossible to completely eliminate the tumor.

To determine the relative importance of drug concentration and exposure time, spheroids were exposed to different drug concentrations such that the product of exposure time and drug concentration, also known as the area under the curve (AUC), was held constant (Fig. 5b). The exposure times ranged from $1.8 \mathrm{~h}$ for the highest concentration $(50 \mathrm{nM})$ to $90 \mathrm{~h}$ for the lowest concentration $(1 \mathrm{nM})$. Each of the investigated paclitaxel concentrations were within the clinically relevant range (Gianni et al., 1995). 
More spheroid shrinkage was seen at lower concentrations because longer exposure ensured complete drug penetration (Fig. 5b). Longer exposure also ensured that drug encountered more cells passing through the responsive cell-cycle phases. This result that longer exposure yielded greater tumor shrinkage is consistent with previously reported models with cell-cycle phase specific drugs (Panetta, 1997; Shochat et al., 1999).

\subsection{Drug effects on tumor growth}

The effects of paclitaxel and 5FU on human tumors in vivo were simulated by adding pharmacokinetics to the tumor growth model. The time dependence of drug concentrations in the blood plasma and at the tumor periphery was obtained by solving the multi-compartment models (Eqs. (20) and (21)). In the clinic, the dosage ranges for paclitaxel and $5 \mathrm{FU}$ are $135-275 \mathrm{mg} / \mathrm{m}^{2}$ (Perez, 1998) and $1600-2800 \mathrm{mg} / \mathrm{m}^{2}$ (Leichman, 1999; Thomas and Zalcberg, 1998), respectively. In the simulations, dosages of 225 and $2100 \mathrm{mg} / \mathrm{m}^{2}$ were used for paclitaxel and $5 \mathrm{FU}$ respectively, which correspond to dosage concentrations of $69.3 \mu \mathrm{M}$ and $2.16 \mathrm{mM}$ for the average patient. Single $24 \mathrm{~h}$ infusions were simulated for both drugs.
Paclitaxel was present in tumor tissue at physiologically relevant concentrations for longer than 5FU (Fig. 6a and c), despite the fact that the effective diffusion of paclitaxel is an order of magnitude lower than that of 5FU. This behavior was caused by the slow clearance of paclitaxel from the plasma; drug was present in the plasma at relevant concentrations for approximately $60 \mathrm{~h}$ after infusion (inset Fig. 6c). By contrast, 5FU was cleared from the blood within an hour after infusion (inset Fig. 6a).

Administration of paclitaxel caused similar reduction in the tumor volume compared to 5FU, despite its lower toxicity and cell-cycle specificity. Both drugs initially caused tumors to decrease in volume (Fig. 6b and d). As the drugs washed out, cells began to proliferate and the tumors regrew to their original volumes. Tumors treated with paclitaxel and 5FU reached their minimum volumes in ten and three days, respectively (Fig. $6 \mathrm{~b}$ and $\mathrm{d}$ ). This difference was primarily caused by the greater retention of paclitaxel, which in turn was due to its slower diffusion and clearance. In addition, the cell-cycle specific action of 5FU required a relatively high concentration that was not maintained throughout most of the tumor. This result shows that a drug such as paclitaxel that exhibits lower cytotoxicity in monolayer cultures can be more effective in a

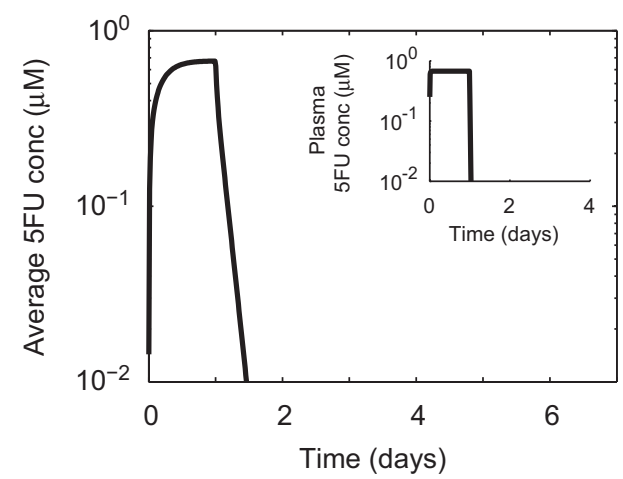

C

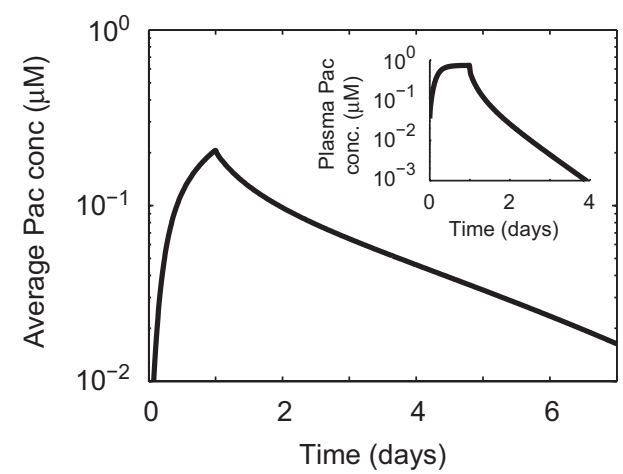

b

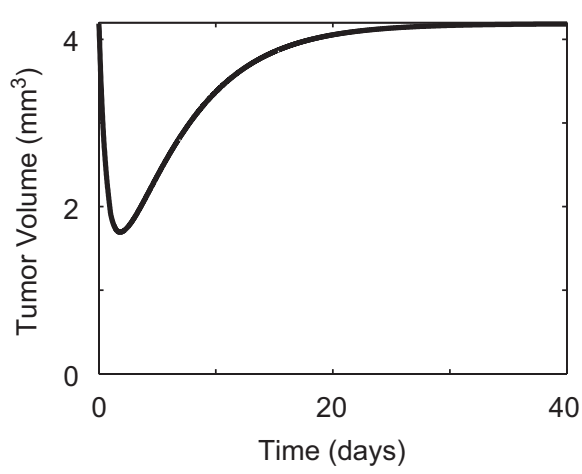

d

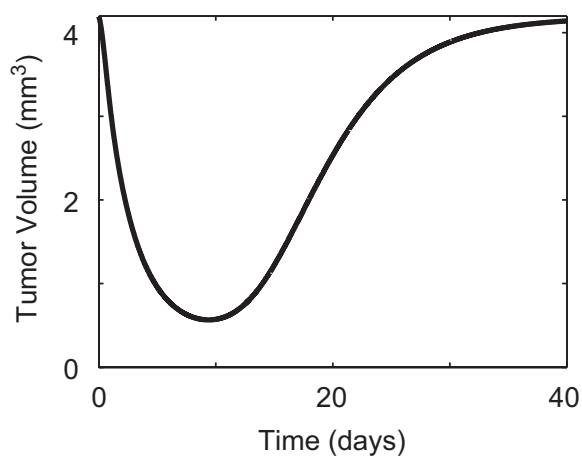

Fig. 6. Effects of 5-fluorouracil (a and b) and paclitaxel (c and d) on simulations of tumor growth. Pharmacokinetics were incorporated by varying drug concentration at the tumor periphery according to the solution of the multi-compartmental models. Both drugs were administered intravenously for $24 \mathrm{~h}$. Figures (a) and (c) show the average tissue concentration of paclitaxel and 5-fluorouracil, respectively. The insets in figures (a) and (c) show the drug concentration in plasma as a function of time. Due to slow diffusion and clearance paclitaxel is retained in the tumor for longer than 5-fluorouracil. Figure (b) and (d) show the extent of spheroid shrinkage following the administration of 5-fluorouracil and paclitaxel, respectively. 


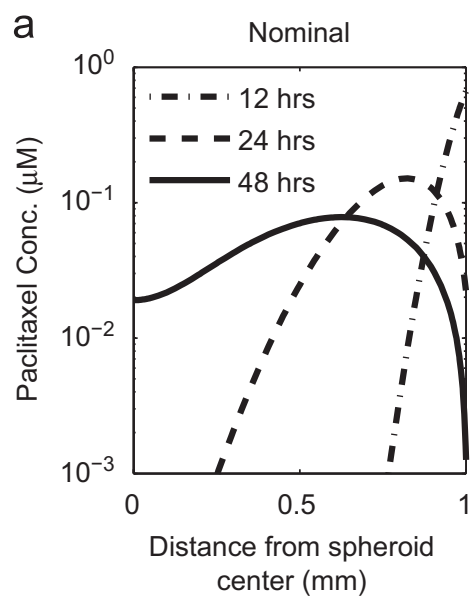

d

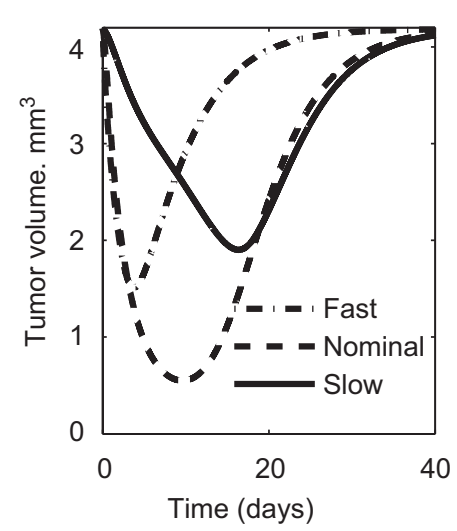

b

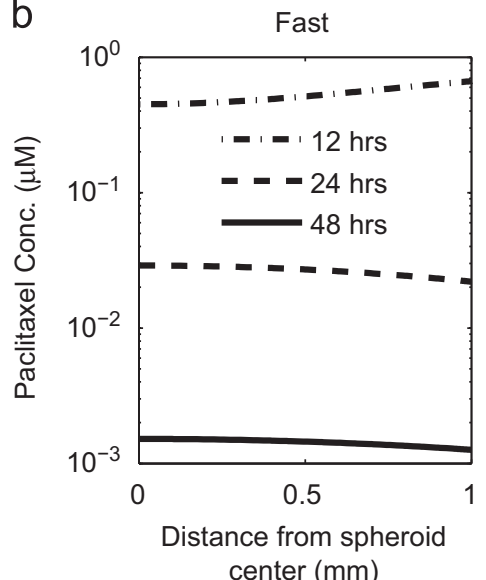

e

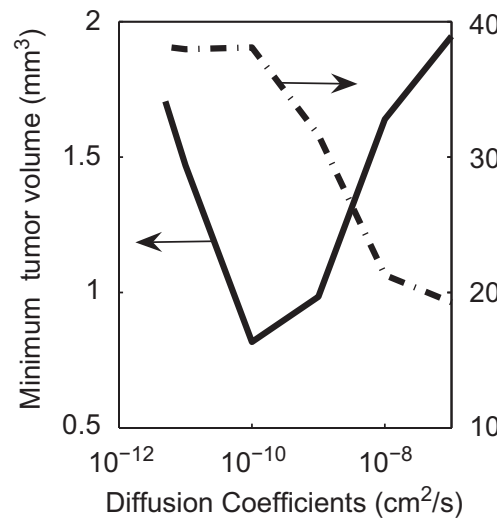

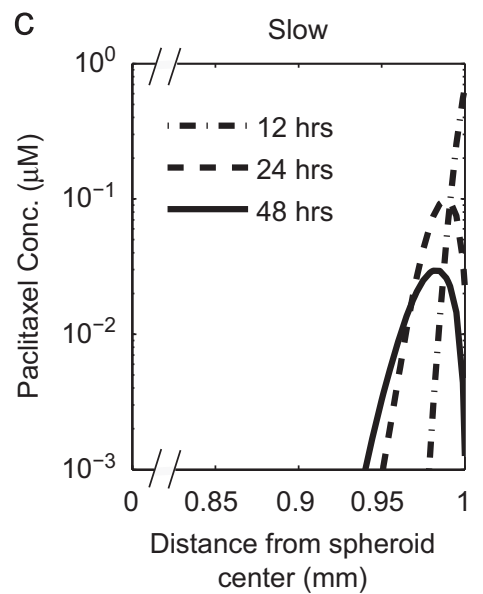

$f$

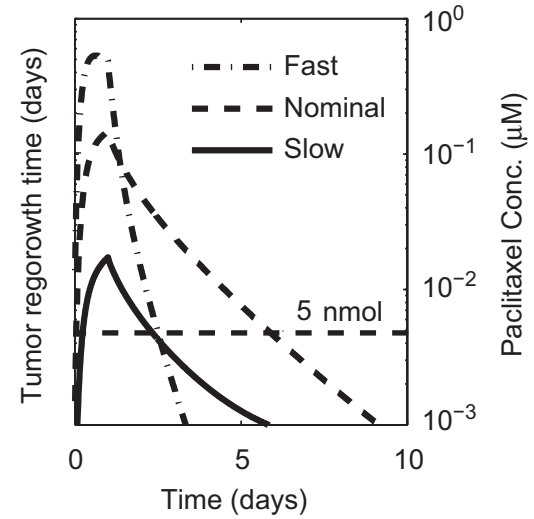

Fig. 7. Effect of different effective diffusion coefficients on drug response in tumors. The results are shown for three different cases with effective diffusion coefficients: $10^{-7}, 10^{-9}$ and $10^{-11} \mathrm{~cm}^{2} / \mathrm{s}$; that are referred to as fast diffusion, nominal diffusion and slow diffusion, respectively. (a-c) Spatial drug profile at 12,24 , and $48 \mathrm{~h}$ after a $24 \mathrm{~h}$ infusion for (a) nominal diffusion coefficient, (b) fast diffusion coefficient, and (c) slow diffusion. As the diffusion is decreases from fast to slow, drug concentration gradients become steeper and maximum concentration in the tumor was lower. (d) Effect of diffusion on the extent of tumor shrinkage and the time of recovery. (e) A maxima in tumor shrinkage was found for a diffusion coefficient around $10^{-10} \mathrm{~cm}^{2} / \mathrm{s}$. Beneath a diffusion coefficient at $10^{-10} \mathrm{~cm}^{2} / \mathrm{s}$, regrowth time reached a plateau. (f) Effect of diffusion on the average paclitaxel concentration in tumors. The nominal diffusion coefficient had the greatest retention.

tumor tissues than a drug such as $5 \mathrm{FU}$ with higher toxicity due to the effects of drug diffusion and clearance.

\subsection{Effect of diffusion coefficient on tumor growth}

The effect of transport limitations on chemotherapeutic efficacy was determined by perturbing the paclitaxel diffusion coefficient by four orders of magnitude from the nominal measured coefficient $\left(1.1 \times 10^{-9} \mathrm{~cm}^{2} / \mathrm{s}\right)$. The effects of a fast $\left(10^{-7} \mathrm{~cm}^{2} / \mathrm{s}\right)$ and a slow $\left(10^{-11} \mathrm{~cm}^{2} / \mathrm{s}\right)$ diffusing drug were simulated for a $24 \mathrm{~h}$ infusion and using the three compartment paclitaxel pharmacokinetic model.

For the nominal diffusion case, the drug concentration $12 \mathrm{~h}$ after infusion was high at the periphery and low at the center (Fig. 7a). As the plasma concentration dropped with time ( 24 and $48 \mathrm{~h}$ ), a maximum formed in the concentration profile indicating that drug was simultaneously diffusing into the tumor center and being transported back into the blood. With increasing time the gradients completely reversed direction and drug slowly cleared from the entire tumor. For the fast diffusing drug, the gradients were considerably flatter and the drug concentration mirrored the plasma concentration in all regions of the tumor (Fig. 7b). For the slow diffusing drug, the gradients were much steeper and drug never reached the central region of the tumor (Fig. 7c).

By varying the drug diffusion coefficient an optimum was found that resulted in the greatest drug efficacy. For all values of the diffusion coefficient, tumor volume decreased when drug was present at the highest concentrations and the tumors regrew as the drug was washed out (Fig. 7d). The fast and slow diffusing drugs did not decrease tumor volume as much as nominal paclitaxel (Fig. 7d). Regrowth took comparable times for the slow diffusing drug and nominal paclitaxel (Fig. 7d). As the drug diffusion coefficient decreased, a maximum was reached in the extent of tumor shrinkage and the time for regrowth reached a plateau (Fig. 7e). This plateau existed because slow diffusing drugs had lower retention times. The maximum in tumor shrinkage occurred because 
the diffusion coefficient had competing effects on drug efficacy: as the diffusion coefficient decreased, the initial concentration decreased and the drug retention time increased (Fig. 7f). Fast diffusing drugs rapidly penetrated the tumor but were washed out quickly. Slow diffusing drugs did not penetrate efficiently but were retained in the tissue much longer. For the fast, nominal, and slow diffusion cases, drug remained at a physiologically relevant concentration $(>5 \mathrm{nM})$ for 2,5 , and 2 days, respectively (Fig. 7f).

The optimum diffusion coefficient was determined to be $\sim 1 \times 10^{-10} \mathrm{~cm}^{2} / \mathrm{s}$ (Fig. 7e), which is an order of magnitude less than that of paclitaxel. The drug transport Eq. (4) was derived using an effective diffusion coefficient that implicitly accounts for more complex phenomena such as intracellular drug binding and degradation. Precise quantitative predictions would be affected by the incorporation of these effects. However, the qualitative behavior of the model would most likely be unaffected. This result suggests that the efficacy of paclitaxel could be improved by decreasing the diffusion coefficient by conjugation to a particle or vesicle, for example. The diffusion coefficient through tumor tissue is inversely correlated to the molecular weight $\left(D \propto 1 /(M W)^{3 / 4}\right.$ (Swabb et al., 1974)), suggesting that increasing the molecular weight of paclitaxel to approximately 20,000 molecular weight units would increase its efficacy.

\subsection{Kinetic drug resistance}

Kinetic drug resistance is the reduction in efficacy of a cell-cycle specific drug due to a limited number of cells in the susceptible cell-cycle phase. We hypothesized that tracking cell-cycle phases in three-dimensional tissues would give better a prediction of drug efficacy. To investigate the possible role of kinetic resistance two artificial cases were created in which the death rate was increased five-fold and the proliferation rate was decreased three-fold. The first, cell-cycle specific (CCS) model tracked all cell-cycle phases as described earlier. The second, cellcycle non-specific (CCNS) model contained only proliferating $(\mathrm{G} 1 / \mathrm{S} / \mathrm{G} 2 / \mathrm{M})$, quiescent (G0) and dead cells. In the CCS model paclitaxel killed only $\mathrm{G} 2$ and $\mathrm{M}$ cells, whereas in the CCNS model all proliferating $(\mathrm{G} 1 / \mathrm{S} / \mathrm{G} 2 / \mathrm{M})$ cells were killed. The linear death rate for the CCNS model was matched to the initial death rate of the CCS model.

Kinetic resistance causes a biphasic pattern of cell death in monolayer culture, in which the population initially diminishes quickly as all susceptible cells die, followed by a slower period in which cell death is limited by the rate of cell transition into the susceptible phase (Fig. 8a). However, biphasic cell death was not observed for the nominal paclitaxel, because the rate of drug-induced cell death was proportional to the rate of proliferation (Fig. 8a). The proportionality of these rates caused cells a

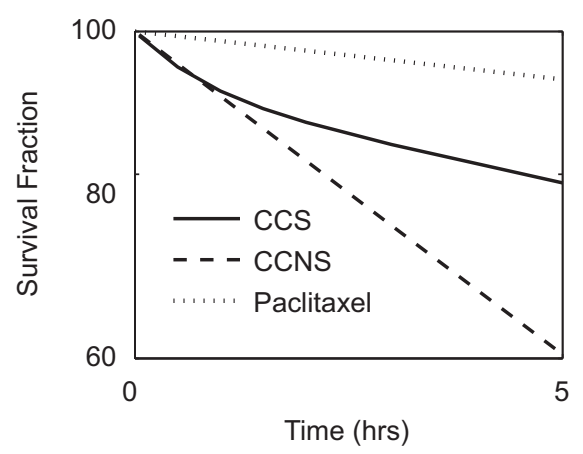

C

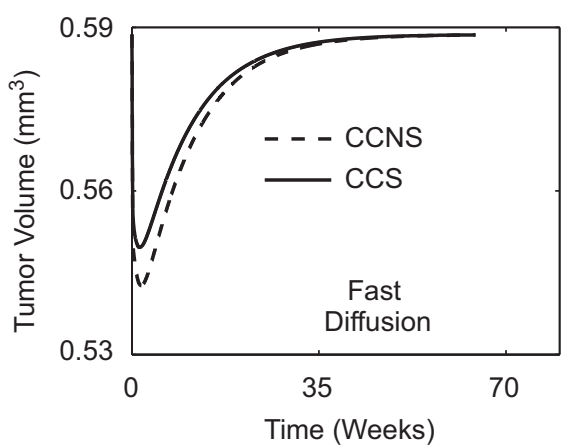

b

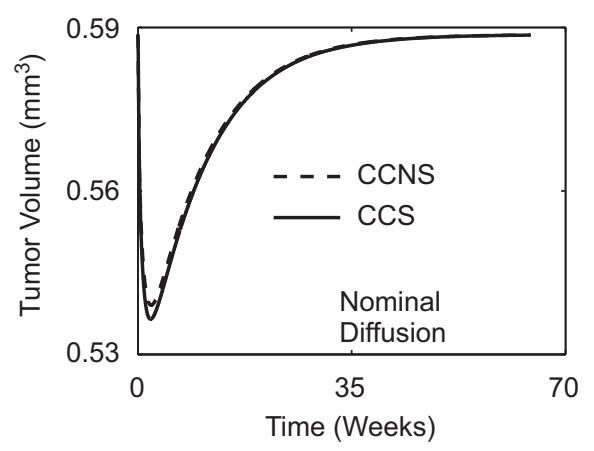

d

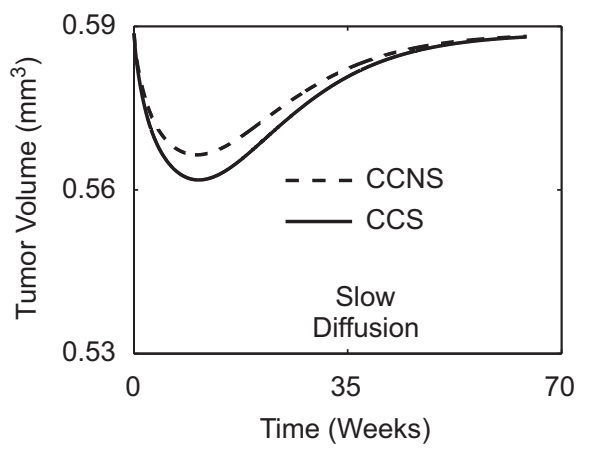

Fig. 8. Kinetic resistance had a minimal effect in three-dimensional tumors. (a) Cytotoxicity of paclitaxel for cell-cycle specific and cell-cycle non-specific drugs as a function of exposure time. Death and proliferation rates were increased 5-fold and decreased 3-fold, respectively, for the CCS and CCNS drugs. The response is linear for the CCNS drug and biphasic for the CCS drug. (b-d) Comparison between the administration of the CCS and CCNS drugs on tumors with (b) nominal diffusion, (c) fast diffusion and (d) slow diffusion. 
in the susceptible phases to be continuously replenished and prevented drug from significantly affecting the cellcycle phase fractions. Because of this minimal effect in the nominal case, the death and proliferation rates were adjusted in the artificial CCS and CCNS models to accentuate the biphasic pattern and the role of kinetic resistance (Fig. 8a).

At nominal drug diffusion coefficients the difference between the CCNS and CCS cases was small (Fig. 8b). When the diffusion coefficient was increased the CCNS model over-predicted the rate of tumor reduction (Fig. 8c), which parallels the effects observed in monolayer culture (Fig. 8a). However, when the diffusion coefficient was decreased, the CCNS model under-predicted the rate of tumor reduction (Fig. 8d).

The simulation identified slight differences in the cellcycle phase profiles of the CCS and CCNS models, and showed that a cell-cycle non-specific model could reasonably predict tumor reduction for cases of altered growth and diffusion. Kinetic resistance did not appreciably affect drug efficacy for two reasons: (1) kinetic resistance is intrinsically a minor effect that does not alter the initial rate of cell death, which is the major cause of drug-induced death in tumors; and (2) cell-cycle transition times were considerable faster than the nominal rates of growth, death, and diffusion, which prevented drugs from having long-term effects on cell-cycle phase populations. These results suggest that explicitly tracking different cell-cycle phases is not essential for predicting drug effects in solid tumors, and also suggest that designing cell-cycle targeting drugs may not offer unique advantages to cell-cycle nonspecific drugs.

\subsection{Effect of proliferation fraction on tumor growth}

The effect of the tumor proliferation fraction on the efficacy of chemotherapy was simulated to determine the response of tumors with less proliferating cells. The proliferation fraction of a tumor is defined as the ratio of cells in the cycling phases $(\mathrm{G} 1, \mathrm{~S}, \mathrm{G} 2$, and $\mathrm{M})$ to the total number of living cells. Tumors have been identified with a wide range of proliferation fractions from $1 \%$ to $70 \%$ (Gardner, 2002a). This large distribution is associated with considerable difference in cell-cycle times (30-60 h), apoptotic cell fractions $(0.1-4 \%)$; and $\mathrm{S}$-phase fractions (1-40\%) (Gardner, 2002a). The proliferation fraction has important implications on therapy because most

Table 4

Proliferation metrics of nominal tumor and slow growing tumors

\begin{tabular}{lll}
\hline & Nominal tumor & Slow growing tumor \\
\hline Proliferation fraction (\%) & 63 & 17 \\
G0 phase fraction (\%) & 37 & 83 \\
S phase fraction (\%) & 26 & 7 \\
Saturated size (radius) (mm) & 1 & 0.54 \\
\hline
\end{tabular}

chemotherapeutic agents are only effective on the proliferation cells.

The effect of a series of $24 \mathrm{~h}$ paclitaxel infusions was simulated for two tumors with different proliferation fractions. The nominal tumor simulated above represents a fast growing tumor with a high proliferation fraction (63\%; Table 4). A slow-growing tumor was created by increasing the maximum transition rate from $\mathrm{G} 1$ to $\mathrm{G} 0$ $\left(\mu_{G 0, \text { max }}^{G 1}\right)$ by a factor of 10 . Since $\mu_{G 0, \text { max }}^{G 1}$ was found to have the greatest effect on the proliferation fraction, only this one parameter was perturbed to minimize cross parameter effects. The resultant slow-growing tumor had a proliferation fraction of $17 \%$ and saturated radius of $0.54 \mathrm{~mm}$ (Table 4). The S-phase fraction, another indicator of tumor growth, was considerably different between the two tumors (26 compared to $7 \%$; Table 4 ).

Overall volume reduction was greater for the slower growing tumor after several rounds of paclitaxel administration, even though the fast growing tumor had a greater volume reduction immediately following the first infusion

a

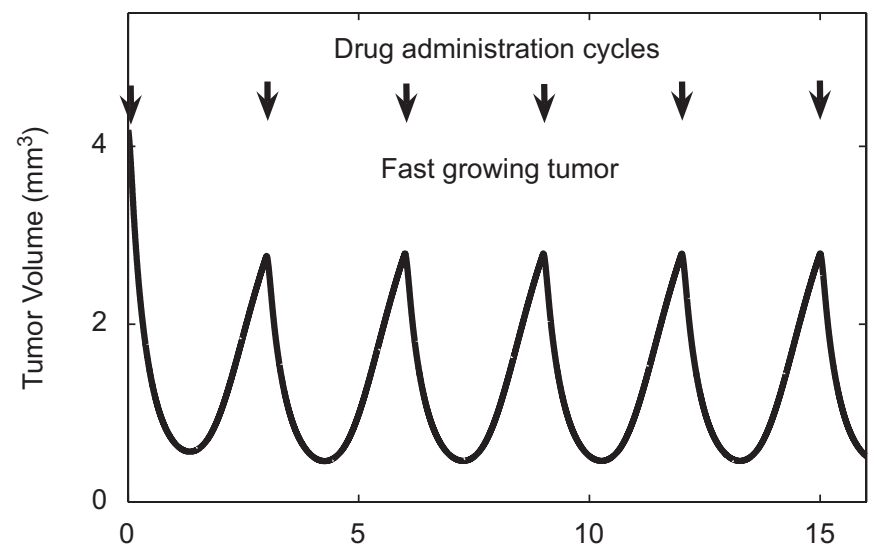

b

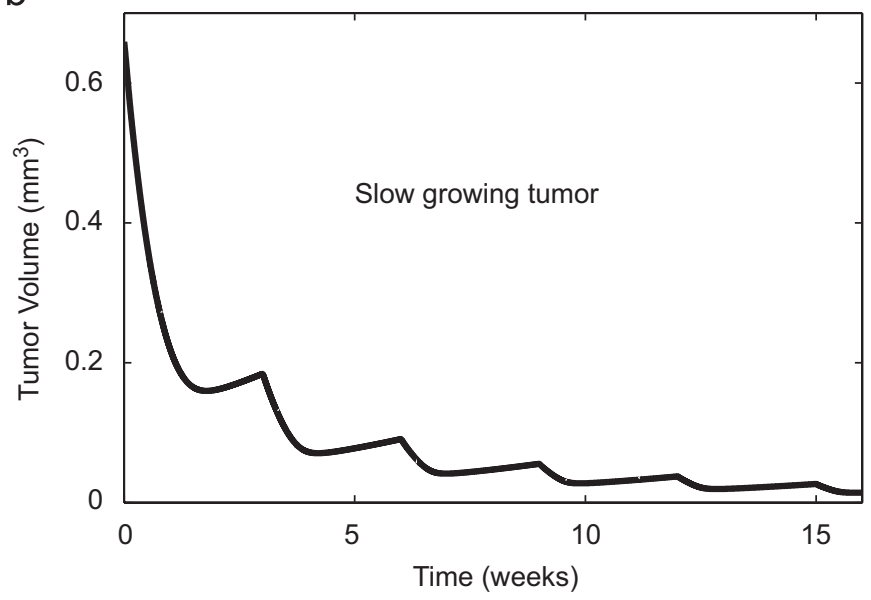

Fig. 9. Effect of multiple paclitaxel infusions spaced every 3 weeks on (a) a fast growing and (b) a slow-growing tumor. Paclitaxel was more effective against the slow growing tumor even though drug had a greater initial effect on the fast growing tumor. The greater proliferative fraction caused the tumor to regrow faster in the time between two successive drug administrations. 
(Fig. 9). Administration of paclitaxel in a three week cycle was sufficient to completely eliminate the slow-growing tumor (Fig. 9b) but was not able to clear the fast growing tumor (Fig. 9a). This unanticipated result that successive paclitaxel administration was more effective on slow growing tumors was primarily attributed to tumor regrowth. After the first infusion, regrowth began after twelve days for the slow-growing tumor, compared to nine days for the fast growing tumor (Fig. 9). For the slowgrowing tumor, the rate of drug-induced death was greater than the rate of regrowth, even though the death rate was considerably less than that of the fast growing tumor. In the fast growing tumor, the rate of regrowth was able to overcome the death induced by paclitaxel. This observation that regrowth is a major hindrance to chemotherapy is supported by clinical trials showing that slow-growing tumors are more responsive to chemotherapy (Choyke et al., 1987; Kim and Tannock, 2005).

\section{Conclusions}

A tumor growth model has been developed that incorporates cell metabolism, molecular diffusion, cellcycle specific drug cytotoxicity, and multi-compartment pharmacokinetics. The model was able to predict the distribution of cell-cycle phases that have been previously experimentally observed in tumors. The simulated effects of two drugs with different transport characteristics, paclitaxel and 5FU, demonstrated the balance between drug diffusion, clearance, and cytotoxicity. Hypothetical drugs with intermediate diffusion coefficients had greater efficacy than fast or slow diffusing drugs demonstrating that the transport through tissue is a trade off between penetration and retention. The simulations showed that cell-cycle heterogeneity had a small but identifiable effect, suggesting that cell-cycle targeting drugs may not offer unique advantages over cell-cycle non-specific drugs. The model simulations also showed that slow-growing tumors are more responsive to chemotherapy because regrowth between drug administrations cannot compete with drug toxicity even though cells are less responsive to drugs due to a lower proliferation fraction.

These simulation results have important therapeutic implications. The results demonstrate the importance of diffusion, and suggest that three-dimensional cultures are useful for determining therapeutic effects in vitro (Kasinskas and Forbes, 2006, 2007; Kim and Forbes, 2007) that cannot be determined in monolayer cultures. The prediction that reducing diffusivity of paclitaxel increases its efficacy should be investigated by measuring the effects of drugs conjugated to nano-particles (Han et al., 2006; Hong et al., 2006). The results also imply that quantifying the proliferation fraction in the tumors of cancer patients would enhance prediction of therapeutic efficacy. This prediction could be investigated in a clinical setting by measuring proliferation and quiescence in tumor biopsies.

\section{Acknowledgments}

This work was supported by the National Institute of Health (Grant no. 1 R21 CA112335-01A1), the National Science Foundation (Grant no. DMI-0531171), and the Rays of Hope (Springfield, MA).

\section{References}

Au, J.L., Li, D., Gan, Y., Gao, X., Johnson, A.L., Johnston, J., Millenbaugh, N.J., Jang, S.H., Kuh, H.J., Chen, C.T., Wientjes, M.G., 1998. Pharmacodynamics of immediate and delayed effects of paclitaxel: role of slow apoptosis and intracellular drug retention. Cancer Res. 58, 2141-2148.

Au, J.L., Jang, S.H., Zheng, J., Chen, C.T., Song, S., Hu, L., Wientjes, M.G., Kuh, H.J., 2001. Determinants of drug delivery and transport to solid tumors: computational model of intracellular pharmacokinetics of paclitaxel. J. Control Release 74, 31-46.

Au, J.L., Jang, S.H., Wientjes, M.G., 2002. Clinical aspects of drug delivery to tumors. J. Control Release 78, 81-95.

Basse, B., Baguley, B.C., Marshall, E.S., Joseph, W.R., van Brunt, B., Wake, G., Wall, D.J., 2003. A mathematical model for analysis of the cell cycle in cell lines derived from human tumors. J. Math Biol. 47, 295-312.

Basse, B., Baguley, B.C., Marshall, E.S., Joseph, W.R., van Brunt, B., Wake, G., Wall, D.J., 2004. Modelling cell death in human tumour cell lines exposed to the anticancer drug paclitaxel. J. Math Biol. 49, 329-357.

Bauer, K.D., Keng, P.C., Sutherland, R.M., 1982. Isolation of quiescent cells from multicellular tumor spheroids using centrifugal elutriation. Cancer Res. 42, 72-78.

Bertuzzi, A., D’Onofrio, A., Fasano, A., Gandolfi, A., 2003. Regression and regrowth of tumour cords following single-dose anticancer treatment. Bull. Math Biol. 65, 903-931.

Brown, J., 2002. Tumor microenvironment and the response to anticancer therapy. Cancer Biol. Ther. 1, 453-458.

Brown, P.N., Hindmarsh, A.C., Petzold, L.R., 1994. Using Krylov methods in the solution of large-scale differential-algebraic systems. SIAM J. Sci. Comput. 15, 1467-1488.

Brown, P.N., Hindmarsh, A.C., Petzold, L.R., 1995. DASPK, Santa Barbara, CA.

Carlsson, J., 1977. A proliferation gradient in three-dimensional colonies of cultured human glioma cells. Int. J. Cancer 20, 129-136.

Casciari, J.J., Sotirchos, S.V., Sutherland, R.M., 1992. Mathematical modelling of microenvironment and growth in EMT6/Ro multicellular tumour spheroids. Cell Prolif. 25, 1-22.

Choyke, P., Zeman, R., Gootenberg, J., Greenberg, J., Hoffer, F., Frank, J., 1987. Thymic atrophy and regrowth in response to chemotherapy: CT evaluation. Am. J. Roentgenol. 149, 269-272.

Costello, L.C., Franklin, R.B., 1994. Bioenergetic theory of prostate malignancy. Prostate 25, 162-166.

Crank, J., 1984. Free and Moving Boundary Problems. Clarendon Press, New York.

Daniel, B., Harkin, D., Johnston, P., 2003. 5-Fluorouracil: mechanisms of action and clinical strategies. Nat. Rev. Cancer 5, 330-338.

Darzynkiewicz, Z., Traganos, F., Melamed, M.R., 1980. New cell cycle compartments identified by multiparameter flow cytometry. Cytometry $1,98-108$.

Dethlefsen, L.A., Bauer, K.D., Riley, R.M., 1980. Analytical cytometric approaches to heterogeneous cell populations in solid tumors: a review. Cytometry 1, 89-108.

Durand, R.E., 1990. Multicell spheroids as a model for cell kinetic studies. Cell Tissue Kinet. 23, 141-159.

El-Khoueiry, A.B., Lenz, H.J., 2006. Should continuous infusion 5-fluorouracil become the standard of care in the USA as it is in Europe? Cancer Invest. 24, 50-55. 
Finlayson, B.A., 1980. Nonlinear Analysis in Chemical Engineering. McGraw-Hill International Book Co., New York.

Folkman, J., 1971. Tumor angiogenesis: therapeutic implications. N. Engl. J. Med. 285, 1182-1186.

Freyer, J.P., 1998. Decreased mitochondrial function in quiescent cells isolated from multicellular tumor spheroids. J. Cell Physiol. 176, 138-149.

Freyer, J.P., Schor, P.L., 1989. Regrowth kinetics of cells from different regions of multicellular spheroids of four cell lines. J. Cell Physiol. 138, 384-392.

Freyer, J.P., Sutherland, R.M., 1980. Selective dissociation and characterization of cells from different regions of multicell tumor spheroids. Cancer Res. 40, 3956-3965.

Gardner, S.N., 2000. A mechanistic, predictive model of dose-response curves for cell cycle phase-specific and -nonspecific drugs. Cancer Res. $60,1417-1425$.

Gardner, S.N., 2002a. Cell cycle phase-specific chemotherapy: computational methods for guiding treatment. Cell Cycle 1, 369-374.

Gardner, S.N., 2002b. Modeling multi-drug chemotherapy: tailoring treatment to individuals. J. Theor. Biol. 214, 181-207.

Gianni, L., Kearns, C.M., Giani, A., Capri, G., Vigano, L., Lacatelli, A., Bonadonna, G., Egorin, M.J., 1995. Nonlinear pharmacokinetics and metabolism of paclitaxel and its pharmacokinetic/pharmacodynamic relationships in humans. J. Clin. Oncol. 13, 180-190.

Grantab, R., Sivananthan, S., Tannock, I.F., 2006. The penetration of anticancer drugs through tumor tissue as a function of cellular adhesion and packing density of tumor cells. Cancer Res. 66, 1033-1039.

Han, G., You, C.C., Kim, B.J., Turingan, R.S., Forbes, N.S., Martin, C.T., Rotello, V.M., 2006. Light-regulated release of DNA and its delivery to nuclei by means of photolabile gold nanoparticles. Angew. Chem. Int. Ed. Engl. 45, 3165-3169.

Helmlinger, G., Sckell, A., Dellian, M., Forbes, N.S., Jain, R.K., 2002. Acid production in glycolysis-impaired tumors provides new insights into tumor metabolism. Clin. Cancer Res. 8, 1284-1291.

Hong, R., Han, G., Fernandez, J.M., Kim, B.J., Forbes, N.S., Rotello, V.M., 2006. Glutathione-mediated delivery and release using monolayer protected nanoparticle carriers. J. Am. Chem. Soc. 128, 1078-1079.

Jackson, R.C., 1989. The problem of the quiescent cancer cell. Adv. Enzyme Regul. 29, 27-46.

Jackson, T.L., 2003. Intracellular accumulation and mechanism of action of doxorubicin in a spatio-temporal tumor model. J. Theor. Biol. 220, 201-213.

Jackson, T.L., Byrne, H.M., 2000. A mathematical model to study the effects of drug resistance and vasculature on the response of solid tumors to chemotherapy. Math Biosci. 164, 17-38.

Jain, R., 1996. Delivery of molecular medicine to solid tumors. Science 271, 1079-1080.

Jain, R., 1999. Transport of molecules, particles, and cells in solid tumors. Annu. Rev. Biomed. Eng. 1, 241-263.

Kasinskas, R.W., Forbes, N.S., 2006. Salmonella typhimurium specifically chemotax and proliferate in heterogeneous tumor tissue in vitro. Biotechnol. Bioeng. 94, 710-721.

Kasinskas, R.W., Forbes, N.S., 2007. Salmonella typhimurium lacking ribose chemoreceptors localize in tumor quiescence and induce apoptosis. Cancer Res. 67, 3201-3209.

Kearns, C.M., Gianni, L., Egorin, M.J., 1995. Paclitaxel pharmacokinetics and pharmacodynamics. Semin. Oncol. 22, 16-23.

Kim, B.J., Forbes, N.S., 2007. Flux analysis shows that hypoxia-induciblefactor-1-alpha minimally affects intracellular metabolism in tumor spheroids. Biotechnol. Bioeng. 96, 1167-1182.

Kim, J.J., Tannock, I.F., 2005. Repopulation of cancer cells during therapy: an important cause of treatment failure. Nat. Rev. Cancer 5, 516-525.

Konerding, M.A., Malkusch, W., Klapthor, B., van Ackern, C., Fait, E., Hill, S.A., Parkins, C., Chaplin, D.J., Presta, M., Denekamp, J., 1999.
Evidence for characteristic vascular patterns in solid tumours: quantitative studies using corrosion casts. Br. J. Cancer 80, 724-732.

Kufe, D.W., Major, P.P., 1981. 5-Fluorouracil incorporation into human breast carcinoma RNA correlates with cytotoxicity. J. Biol. Chem. 256, 9802-9805.

Kuh, H.J., Jang, S.H., Wientjes, M.G., Weaver, J.R., Au, J.L., 1999. Determinants of paclitaxel penetration and accumulation in human solid tumor. J. Pharmacol. Exp. Ther. 290, 871-880.

Kuh, H.J., Jang, S.H., Wientjes, M.G., Au, J.L., 2000. Computational model of intracellular pharmacokinetics of paclitaxel. J. Pharmacol. Exp. Ther. 293, 761-770.

Lankelma, J., 2002. Tissue transport of anti-cancer drugs. Curr. Pharm. Des. 8, 1987-1993.

Lankelma, J., Fernandez Luque, R., Dekker, H., Schinkel, W., Pinedo, H.M., 2000. A mathematical model of drug transport in human breast cancer. Microvasc. Res. 59, 149-161.

LaRue, K.E., Khalil, M., Freyer, J.P., 2004. Microenvironmental regulation of proliferation in multicellular spheroids is mediated through differential expression of cyclin-dependent kinase inhibitors. Cancer Res. 64, 1621-1631.

Lau, C., Mole, M.L., Copeland, M.F., Rogers, J.M., Kavlock, R.J., Shuey, D.L., Cameron, A.M., Ellis, D.H., Logsdon, T.R., Merriman, J., Setzer, R.W., 2001. Toward a biologically based dose-response model for developmental toxicity of 5-fluorouracil in the rat: acquisition of experimental data. Toxicol. Sci. 59, 37-48.

Leichman, C.G., 1999. Schedule dependency of 5-fluorouracil. Oncology (Williston Park) 13, 26-32.

Levasseur, L.M., Slocum, H.K., Rustum, Y.M., Greco, W.R., 1998. Modeling of the time-dependency of in vitro drug cytotoxicity and resistance. Cancer Res. 58, 5749-5761.

Minchinton, A.I., Tannock, I.F., 2006. Drug penetration in solid tumours. Nat. Rev. Cancer 6, 583-592.

Montalenti, F., Sena, G., Cappella, P., Ubezio, P., 1998. Simulating cancer-cell kinetics after drug treatment: application to cisplatin on ovarian carcinoma. Phys. Rev. E 57, 5877-5887.

Mueller-Klieser, W.F., Sutherland, R.M., 1984. Oxygen consumption and oxygen diffusion properties of multicellular spheroids from two different cell lines. Adv. Exp. Med. Biol. 180, 311-321.

Nederman, T., Carlsson, J., 1984. Penetration and binding of vinblastine and 5-fluorouracil in cellular spheroids. Cancer Chemother. Pharmacol. 13, 131-135.

Nicholson, K.M., Bibby, M.C., Phillips, R.M., 1997. Influence of drug exposure parameters on the activity of paclitaxel in multicellular spheroids. Eur. J. Cancer 33, 1291-1298.

Nogales, E., 2000. Structural insights into microtubule function. Annu. Rev. Biochem. 69, 277-302.

Olive, K.P., Tuveson, D.A., 2006. The use of targeted mouse models for preclinical testing of novel cancer therapeutics. Clin. Cancer Res. 12, 5277-5287.

Panetta, J.C., 1997. A mathematical model of breast and ovarian cancer treated with paclitaxel. Math. Biosci. 146, 89-113.

Perez, E.A., 1998. Paclitaxel in breast cancer. Oncologist 3, 373-389.

Rossow, P.W., Riddle, V.G., Pardee, A.B., 1979. Synthesis of labile, serum-dependent protein in early G1 controls animal cell growth. Proc. Natl. Acad. Sci. USA 76, 4446-4450.

Shah, M.A., Schwartz, G.K., 2001. Cell cycle-mediated drug resistance: an emerging concept in cancer therapy. Clin. Cancer Res. 7, $2168-2181$.

Shochat, E., Hart, D., Agur, Z., 1999. Using computer simulations for evaluating the efficacy of breast cancer chemotherapy protocols. Math. Model Method Appl. Sci. 9, 599-615.

Suggitt, M., Bibby, M.C., 2005. 50 years of preclinical anticancer drug screening: empirical to target-driven approaches. Clin. Cancer Res. 11, 971-981.

Sutherland, R., 1988. Cell and environment interactions in tumor microregions: the multicell spheroid model. Science 240, 177.

Swabb, E.A., Wei, J., Gullino, P.M., 1974. Diffusion and convection in normal and neoplastic tissues. Cancer Res. 34, 2814-2822. 
Tanaka, F., Fukuse, T., Wada, H., Fukushima, M., 2000. The history, mechanism and clinical use of oral 5-fluorouracil derivative chemotherapeutic agents. Curr. Pharm. Biotechnol. 1, $137-164$.

Tannock, I., 1986. Experimental chemotherapy and concepts related to the cell cycle. Int. J. Radat. Biol. 49, 335-355.

Tannock, I., 2001. Tumor physiology and drug resistance. Cancer Metast. Rev. 20, 123-132.

Tannock, I.F., Lee, C.M., Tunggal, J.K., Cowan, D.S., Egorin, M.J., 2002. Limited penetration of anticancer drugs through tumor tissue: a potential cause of resistance of solid tumors to chemotherapy. Clin. Cancer Res. 8, 878-884.

Terret, C., Erdociain, E., Guimbaud, R., Boisdron-Celle, M., McLeod, H.L., Fety-Deporte, R., Lafont, T., Gamelin, E., Bugat, R., Canal, P., Chatelut, E., 2000. Dose and time dependencies of 5-fluorouracil pharmacokinetics. Clin. Pharmacol. Ther. 68, 270-279.

Thomas, D.M., Zalcberg, J.R., 1998. 5-fluorouracil: a pharmacological paradigm in the use of cytotoxics. Clin. Exp. Pharmacol. Physiol. 25, $887-895$.

Tunggal, J.K., Cowan, D.S., Shaikh, H., Tannock, I.F., 1999. Penetration of anticancer drugs through solid tissue: a factor that limits the effectiveness of chemotherapy for solid tumors. Clin. Cancer Res. 5, 1583-1586.
Tyson, J.J., Novak, B., 2001. Regulation of the eukaryotic cell cycle: molecular antagonism, hysteresis, and irreversible transitions. J. Theor. Biol. 210, 249-263.

Tzafriri, A.R., Lerner, E.I., Flashner-Barak, M., Hinchcliffe, M., Ratner, E., Parnas, H., 2005. Mathematical modeling and optimization of drug delivery from intratumorally injected microspheres. Clin. Cancer Res. 11, 826-834.

Ueda, M., Kumagai, K., Ueki, K., Inoki, C., Orino, I., Ueki, M., 1997. Growth inhibition and apoptotic cell death in uterine cervical carcinoma cells induced by 5-fluorouracil. Int. J. Cancer 71, 668-674.

Venkatasubramanian, R., Henson, M.A., Forbes, N.S., 2006. Incorporating energy metabolism into a growth model of multicellular tumor spheroids. J. Theor. Biol. 12, 1.

Ward, J.P., King, J.R., 1997. Mathematical modelling of avasculartumour growth. IMA J. Math. Appl. Med. Biol. 14, 39-69.

Ward, J.P., King, J.R., 2003. Mathematical modelling of drug transport in tumour multicell spheroids and monolayer cultures. Math. Biosci. 181, 177-207.

Wibe, E., Lindmo, T., Kaalhus, O., 1981. Cell kinetic characteristics in different parts of multicellular spheroids of human origin. Cell Tissue Kinet. 14, 639-651.

Zhao, J., Kim, J.E., Reed, E., Li, Q.Q., 2005. Molecular mechanism of antitumor activity of taxanes in lung cancer (Review). Int. J. Oncol. 27, 247-256. 